\title{
Adsorption of phenylurea herbicides by tropical soils
}

\author{
Babatunde Kazeem Agbaogun (D) Klaus Fischer
}

Received: 21 September 2019 / Accepted: 12 February 2020 /Published online: 4 March 2020

(C) The Author(s) 2020

\begin{abstract}
The distribution of pesticides in soils with consequences for their mobility, bioavailability and water contamination is mainly ruled by sorption processes. Such processes are seldom investigated in tropical soils. Thus, specific interactions between tropical soils and most pesticides are widely unknown. Furthermore, the question arises whether the same factors govern adsorption in tropical and temperate soils. Thus, the sorption behaviour of five phenylurea herbicides (PUHs) was studied in eighteen differently composed soils originating from southwestern Nigeria. Sorption data were obtained by equilibrating the soil samples with $0.01 \mathrm{M}$ $\mathrm{CaCl}_{2}$ solutions spiked with increasing concentrations of the target PUHs. The equilibrium data fitted well to the Freundlich isotherm equation $\left(R^{2} \geq 0.96\right)$, delivering the corresponding parameters $\left(K_{\mathrm{f}}\right.$ and $\left.n\right)$. Linear distribution coefficients $\left(K_{\mathrm{d}}\right)$ were also calculated. The Pearson correlation was used to identify the specific soil and herbicide properties that have statistically significant correlations with sorption parameters. High correlations were established for various soil properties $\mathrm{pH}$, cation exchange capacity, organic carbon content, content of amorphous $\mathrm{Fe}$ and $\mathrm{Mn}$ oxides, clay/silt mass proportions) as well as molecular descriptors (octanol-water
\end{abstract}

Electronic supplementary material The online version of this article (https://doi.org/10.1007/s10661-020-8160-2) contains supplementary material, which is available to authorized users.

B. K. Agbaogun $(\bowtie) \cdot K$. Fischer

Department of Analytical and Ecological Chemistry, University of Trier, Trier, Germany

e-mail: chemie2@uni-trier.de partition coefficient $\left(\log K_{\mathrm{ow}}\right)$ and molecular mass $(\mathrm{Mw})$ ) of the moderately hydrophobic herbicides. Monuron, chlorotoluron and isoproturon showed higher affinities for soil than previously reported. The gathered knowledge might assist in the assessment and in the precautionary avoidance of potential risks generated by these compounds in tropical soils.

Keywords Tropical soil $\cdot$ Phenylurea herbicides ·

Adsorption $\cdot$ Soil properties $\cdot K_{\mathrm{f}} \cdot$ Molecular descriptors

\section{Introduction}

Understanding the fate of pesticides in soil is fundamental for the accurate assessment of their environmental risk. It is also essential for the assurance of the safe use of both newly developed and legacy pesticides. The fate of pollutants in the environment is affected by many biogeochemical processes - a complex web of various physical, chemical and biological interactions (Ghafoor et al. 2011) where sorption on organic and mineral surfaces plays a key role. Sorption phenomena ultimately determine the availability of pollutants for biological and chemical degradation in soils (Karickhoff 1984; Murphy and Zachara 1995; Olvera-Velona et al. 2008). On the other hand, the degree to which a pesticide is adsorbed by soil itself is affected by many pedological and pesticide physicochemical properties (Weber et al. 2004; Olvera-Velona et al. 2008; Sanchez-Bayo and Hyne 2011; Hall et al. 2015). The interrelationships among these factors and 
their effects on sorption are still not fully understood, hence the continued research interest.

Among the most important and extensively used classes of pesticides worldwide are the phenylurea herbicides (PUHs) (El-Nahhal et al. 2013). PUHs have been commercialised for more than 50 years (Giacomazzi and Cochet 2004; Green and Young 2006; Baskeyfield et al. 2011). Most often, they are used for pre- or post-emergence control of weeds in diverse cropped areas and vineyards (Chhokar et al. 2008; Wang et al. 2015) and also in non-cropped areas such as roads, railway tracks and homes (Sørensen et al. 2003; Giacomazzi and Cochet 2004; Silkina et al. 2009). Diuron, in particular, is also used as algicide in antifouling paints. As a consequence of their wide use, PUHs have been detected in several environmental compartments as well as in food products around the world (Wang et al. 2015; Lu et al. 2018). Besides the PUHs themselves, some of their metabolites such as 3,4dichloroaniline (3,4-DCA), $N$-(3,4-dichlorophenyl)urea (DCPU) and $N$-(3,4-dichlorophenyl)- $N$-methylurea (DCPMU) have also been detected in natural waters (Eriksson et al. 2007). Some evidence exists that PUHs exert adverse effects in aquatic organisms, small mammals and humans (Blondel et al. 2013; Lu et al. 2018). Specifically, isoproturon, diuron and linuron are suspected to evoke carcinogenic, mutagenic, teratogenic, endocrine-disrupting and cytogenetic effects in animals as well as humans (Orton et al. 2009; Lu et al. 2018). Some of their metabolites have also been reported to be much more harmful to non-target organisms than their parent compounds (Eriksson et al. 2007). Consequently, four PUHs-diuron, chlorotoluron, isoproturon and methabenzthiazuron-were included in the European Commission's list of priority substances for European freshwater resources. Diuron, linuron, fluometuron and neburon were also listed on the US Environmental Protection Agency's Second Drinking Water Contaminant Candidate (Sørensen et al. 2003; Federico et al. 2014).

Thus, concerns about the environmental behaviour of PUHs have increased over the years, raising many scientific issues. Several studies investigated their sorption behaviour in soils (Hance 1965; Grover 1975; FouqueBrouard and Fournier 1996; Sanchez-Camazano et al. 2000; Liyange et al. 2006; Inoue et al. 2006; El-Khattabi et al. 2007; Fernandez-Bayo et al. 2008; Sanchez-Bayo and Hyne 2011; Elgouzi et al. 2012; El-Nahhal et al. 2013; Mendes et al. 2014; Hall et al. 2015). Also,
Blondel et al. (2013) and Langeron et al. (2014) investigated the molecular properties that affect the adsorption coefficient of these herbicides. Nevertheless, most of these studies focused on temperate soils. Furthermore, almost all screening tools to evaluate the fate or mobility of herbicides in soils work with $K_{\mathrm{d}}$ and/or $K_{\text {oc }}$ values derived from temperate soils (Rao et al. 1985; Mendes et al. 2014; Hall et al. 2015). This procedure is not justified as long as the following central question remains unanswered: are distribution coefficients from the temperate soils directly transferable to tropical soils despite the differences in soil types, climate conditions and cropping systems? Currently, no data exists on the phase distribution of PUHs in Nigerian and most other tropical soils to answer this question. Secondly, there are some research gaps regarding the importance of soil physicochemical properties for PUH adsorption, leaving the rules that control the process undiscovered. Therefore, the specific objectives of this study were (i) to determine the sorption behaviour of five commonly used PUHs (linuron, diuron, monuron, chlorotoluron and isoproturon) in a wide range of Nigerian soils, (ii) to identify the physicochemical controls of Nigerian soils on PUH sorption and (iii) to compare the sorption behaviour of these compounds in these soils with the available data, especially from temperate soils. Furthermore, considering the rather hydrophobic and non-ionic nature of PUHs and the body of work pointing out the dominance of soil organic matter (SOM) in their adsorption, we also evaluated the characteristics of PUH sorption in some organic matter-free (OMF) soils. The latter being an attempt to estimate the separate contributions of soil organics and minerals to sorption of PUHs in soils. We believe this knowledge will contribute to the potential use of organic matters, more importantly in solving problems associated with the pollution of ground and surface waters by fairly hydrophobic pesticides.

To achieve these objectives, the experimental studies were focused on the (1) measurement of sorption coefficients of the five PUHs in eighteen contrasting whole soils, (2) measurement of sorption coefficients of two PUHs (linuron and diuron) in few of the soil samples after SOM removal treatment and (3) measurement of sorption kinetics of three PUHs (linuron, diuron and monuron) in twelve whole soils. The results were subjected to statistical analysis against a wide range of soils and PUH properties to identify the trends and correlations. Soil as a three- 
dimensional body reflects, most especially, the impact of climate. Therefore, given the wide difference between temperate and tropical climates, it was assumed that PUH sorption in Nigerian (tropical) soils is different from that of temperate soils. It was also hypothesised that apart from SOM, soil mineral fractions contribute to PUH sorption. Lastly, based on the physicochemical properties of PUHs, the effect of SOM on sorption was expected to increase with increasing $\log K_{\text {ow. }}$.

\section{Materials and methods}

\section{Chemicals}

Unlabelled analytical standards (99\% purity) of diuron (3-(3,4-dichlorophenyl)-1,1-dimethyl-urea), linuron (3-(3,4-dichlorophenyl)-1-methoxy-1-methylurea), monuron (3-(4-chlorophenyl)-1,1-dimethyl-urea) and chlorotoluron (3-(3-chloro-4-methylphenyl)-1,1dimethylurea) were obtained from Sigma-Aldrich (Germany), while isoproturon (3-(4-isopropylphenyl)-1,1dimethylurea) was obtained from Dr. Ehrenstorfer (Augsburg, Germany). The chemical structures and properties of the selected PUHs are shown in Fig. 1 and Table 1. All other reagents were of analytical grade. PUH stock solutions $\left(1 \mathrm{~g} \mathrm{~L}^{-1}\right)$ were prepared in HPLC grade methanol, from where working solutions of $0.25-$ $25 \mathrm{mg} \mathrm{L}^{-1}$ were prepared in $0.01 \mathrm{M} \mathrm{CaCl}_{2} / \mathrm{Milli}-\mathrm{Q}$ water (membraPure, $0.055 \mu \mathrm{s} / \mathrm{cm}$ ) solution.

\section{Soils}

The soils stemmed from southwestern Nigeria, largely from the moist lowland and southern Guinea savannah

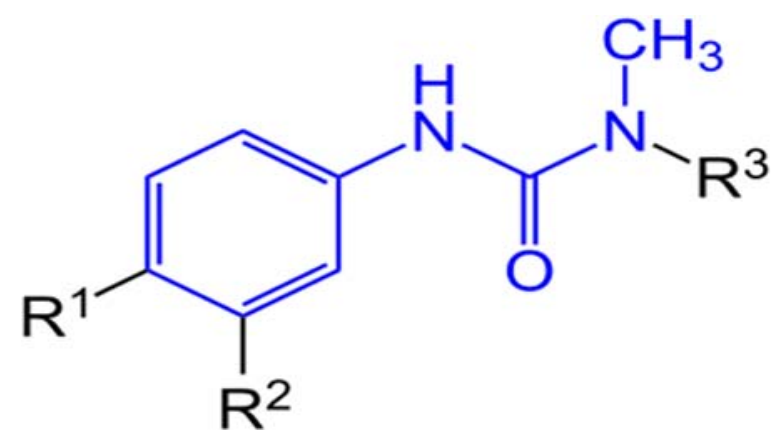

Fig. 1 General structure of PUHs ecological zones. The region is covered with dense forest and savannah vegetation (trees and shrubs), with and without canopy formation (Fagbemi and Shogunle 1995). This region has a temperature of between 28 and $32{ }^{\circ} \mathrm{C}$ (annual average), and a mean annual precipitation of 1000-1500 mm, with the rainy season lasting for 7-8 months. The geomorphology of this area is characterised by two major rock types: (i) arenaceous sedimentary rocks and deposits and (ii) crystalline basement complex rocks. Each rock type has its unique soils. But generally, the soils are ferruginous tropical soils with kaolinite as the dominant clay mineral. The dominant soil types in this region are Arenic Paleudalfs, Rhodic Paleudalfs, Oxic Tropudalfs, Typic Tropudults, Typic Tropaquepts, Oxic Paleudalfs, Oxic Paleustalfs, Aquic Tropopsamments and Typic Ustipsamments (pro parte) according to US soil taxonomy (Fagbemi and Shogunle 1995). These can be broadly classified as Luvisols, Lixisols, Gleysols, and Arenosols according to WRB classification (IUSS Working Group WRB 2014). As observed by Giresse (2008), almost all the tropical soils are fairly represented in the western part of the African continent, hence the choice of this study location.

Eighteen top soils $(0-20 \mathrm{~cm})$ with contrasting characteristics, and representing these major soil types, were collected at different agricultural and non-agricultural fields with the aid of a soil auger. The samples were airdried, passed through a 2-mm sieve and stored at room temperature prior to use. Samples were extensively characterised using standard methods. Briefly, soil $\mathrm{pH}$ was measured in 1:2.5 (w/v) soil/ $0.01 \mathrm{M} \mathrm{CaCl}_{2}$ solution, with a $\mathrm{pH}$ meter. Soil organic carbon (SOC) was determined as the difference between soil total carbon (STC) and soil inorganic carbon (SIC). STC determination was based on complete oxidation of the carbon in previously crushed and oven-dried samples. Measurement was done using an Elemental Analyser EA3000 apparatus (HEKAtech GmbH, Wegberg, Germany). SIC for the samples with $\mathrm{pH}_{\mathrm{CaCl} 2}>6.6$ was determined by destruction of the soil carbonates with $50 \%$ phosphoric acids and by simultaneous measurement of the $\mathrm{CO}_{2}$ evolved by CHNS Elemental Analyser (HEKAtech GmbH, Wegberg, Germany). The effective cation exchange capacity (ECEC) was determined as the sum of extractable cations $(\mathrm{Na}+\mathrm{Ca}+\mathrm{Mg}+\mathrm{Na}+\mathrm{K}+\mathrm{Fe}+\mathrm{Mn}+\mathrm{Al})$ obtained after displacement with $1 \mathrm{M}$ ammonium chloride solution (Shuman and Duncan 1990). Determination of the pedogenic metal oxides $\left(\mathrm{Fe}_{\mathrm{d}}, \mathrm{Al}_{\mathrm{d}}\right.$ and $\left.\mathrm{Mn}_{\mathrm{d}}\right)$ followed 
Table 1 Common names, structures, properties and analytical parameters of the selected phenylureas

\begin{tabular}{|c|c|c|c|c|c|c|c|c|c|c|c|c|}
\hline Common name & Abbr & CAS number & $\mathrm{R}^{1}$ & $\mathrm{R}^{2}$ & $\mathrm{R}^{3}$ & $\log K_{\mathrm{ow}}$ & $\mathrm{Mw}^{\mathrm{a}}$ & $\alpha^{\mathrm{b}}$ & $S^{\mathrm{a}}$ & $\log S$ & $\lambda^{\mathrm{c}}$ & $\mathrm{RT}^{\mathrm{c}}$ \\
\hline Diuron & DIU & $330-54-1$ & $\mathrm{Cl}$ & $\mathrm{Cl}$ & $\mathrm{CH}_{3}$ & 2.60 & 233.1 & 26.2 & 36 & 1.56 & 249 & 8.70 \\
\hline Linuron & LIN & $330-55-2$ & $\mathrm{Cl}$ & $\mathrm{Cl}$ & $\mathrm{OCH}_{3}$ & 3.00 & 249.0 & 27.2 & 64 & 1.81 & 248 & 10.25 \\
\hline Monuron & MON & $150-68-5$ & $\mathrm{Cl}$ & $\mathrm{H}$ & $\mathrm{CH}_{3}$ & 1.81 & 198.0 & 23.9 & 230 & 2.36 & 246 & 5.13 \\
\hline Chlorotoluron & CLT & $15545-48-9$ & $\mathrm{CH}_{3}$ & $\mathrm{Cl}$ & $\mathrm{CH}_{3}$ & 2.51 & 212.0 & 26.1 & 74 & 1.87 & 241 & 7.22 \\
\hline Isoproturon & IPU & $34123-59-6$ & $\left(\mathrm{CH}_{3}\right)_{2} \mathrm{C}$ & $\mathrm{H}$ & $\mathrm{CH}_{3}$ & 2.50 & 206.3 & 28.1 & 70 & 1.85 & 243 & 6.54 \\
\hline
\end{tabular}

$\log K_{\mathrm{ow}}$ is the logarithmic value of octanol/water partition coefficient, $S$ is the water solubility at $20{ }^{\circ} \mathrm{C}\left(\mathrm{mg} \mathrm{L}^{-1}\right), \log S$ is the $\operatorname{logarithmic}$ value of water solubility, $\alpha$ is the molecular polarisability $\left(\mathrm{A}^{3}\right)$ and $\lambda$ is the detection wavelength (nm)

$A b b r$ abbreviation, $M w$ molecular weight $\left(\mathrm{g} \mathrm{mol}^{-1}\right), R T$ retention time (minute)

${ }^{\text {a }}$ Pesticide Properties Database (PPDB 2018)

${ }^{\mathrm{b}}$ Gaussian calculation (Blondel et al. 2013)

${ }^{\mathrm{c}}$ This study

the dithionate-citrate extraction protocol of Mehra and Jackson (1960), while that of the active or amorphous proportions $\left(\mathrm{Fe}_{\mathrm{o}}, \mathrm{Al}_{\mathrm{o}}\right.$ and $\left.\mathrm{Mn}_{\mathrm{o}}\right)$ followed the acid ammonium oxalate extraction protocol of Tamm (1922), as modified by Schwertmann (1964). Here, metal oxides refer collectively to $\mathrm{Fe}, \mathrm{Al}$ and $\mathrm{Mn}$ oxides, (oxy)hydroxides and hydrated oxides. Particle size distributions were determined using the laser diffraction technique, with Malvern Mastersizer 3000 (Malvern Instrument, UK). Briefly, samples (about $2 \mathrm{mg}$ ) were dispersed in $0.1 \mathrm{M} \mathrm{Na}$-pyrophosphate for $12 \mathrm{~h}$, followed by $15 \mathrm{~min}$ of ultrasonication. The suspensions were then transferred to the dispersion unit of the Mastersizer from where aliquots were taken under constant stirring for measurement. Each aliquot was measured five times (at a measuring time of $5 \mathrm{~s}$ per measurement, refractive index of 1.78 , adsorption index of 0.1 , assumed density of $2.6 \mathrm{~g} \mathrm{~cm}^{-3}$ and $8 \%$ obscuration), and each sample was measured in triplicate. An internal standard, nepheline thionate (Minex S4), was similarly measured at interval, for quality control. The scattering data were acquired and processed with Mastersizer 3000 software (Malvern Instrument, UK). Soil mineral identification was done by X-ray diffractometry (XRD) for the particle size fraction $<2 \mu \mathrm{m}$, using Siemens D500 diffractometer with $\mathrm{Cu}-\mathrm{K}_{\alpha}$ radiation. Bulk soil mineralogy was determined on air-dried powder preparations (random mounts), while clay mineralogy was determined on oriented specimens. Five XRD scans were run (one for each powder specimen and four for each oriented preparation), i.e. under dry air condition, after ethylene glycol (EG) solvation, under dimethyl sulfoxide (DMSO) solvation and after heating up to $550{ }^{\circ} \mathrm{C}$. These four scans were necessary to differentiate between the four main clay groups: smectite, illite, chlorite and kaolinite. Data sets of powder and oriented diffraction files were compiled and executed with the Bruker AXS XRD software package DIFFRAC ${ }^{\text {plus }}$. Samples diffractograms were analysed by the DIFFRAC ${ }^{\text {plus }}$ Evaluation (EVA) programme (version $6.0 \mathrm{rev} \mathrm{o}$ ), and Eq. (1) proposed by Biscaye (1965) was applied to obtain the semi-quantitative relationships between the different clay minerals.

$$
\begin{aligned}
\text { Area } 17 \AA \quad(\mathrm{EG}) & +4 \times \text { area } 10 \AA \quad(\mathrm{EG}) \\
& +2 \times \text { area } 7 \AA \quad(\text { air })=100 \%
\end{aligned}
$$

where area $17 \AA$ (EG) corresponds to percentage smectite, $4 \times$ area $10 \AA \quad$ (EG) corresponds to percentage illite and $2 \times$ area $7 \AA$ (air) corresponds to percentage kaolinite + chlorite.

Statistical test results of variability, i.e. mean, coefficient of variation $(\mathrm{CV})$, minimum ( $\mathrm{min}$ ) and maximum (max) of each soil property, were calculated with Excel ${ }^{\circledR}$ (2013) spreadsheet. The physicochemical properties of the samples as well as the statistical test of variability are presented in Table 2.

Soil organic matter removal

Chemical destruction of soil organic matter was done to expose mineral surfaces for subsequent sorption experiments. This was carried out according to a modified method of Lavkulich and Wiens (1970), in sequential 


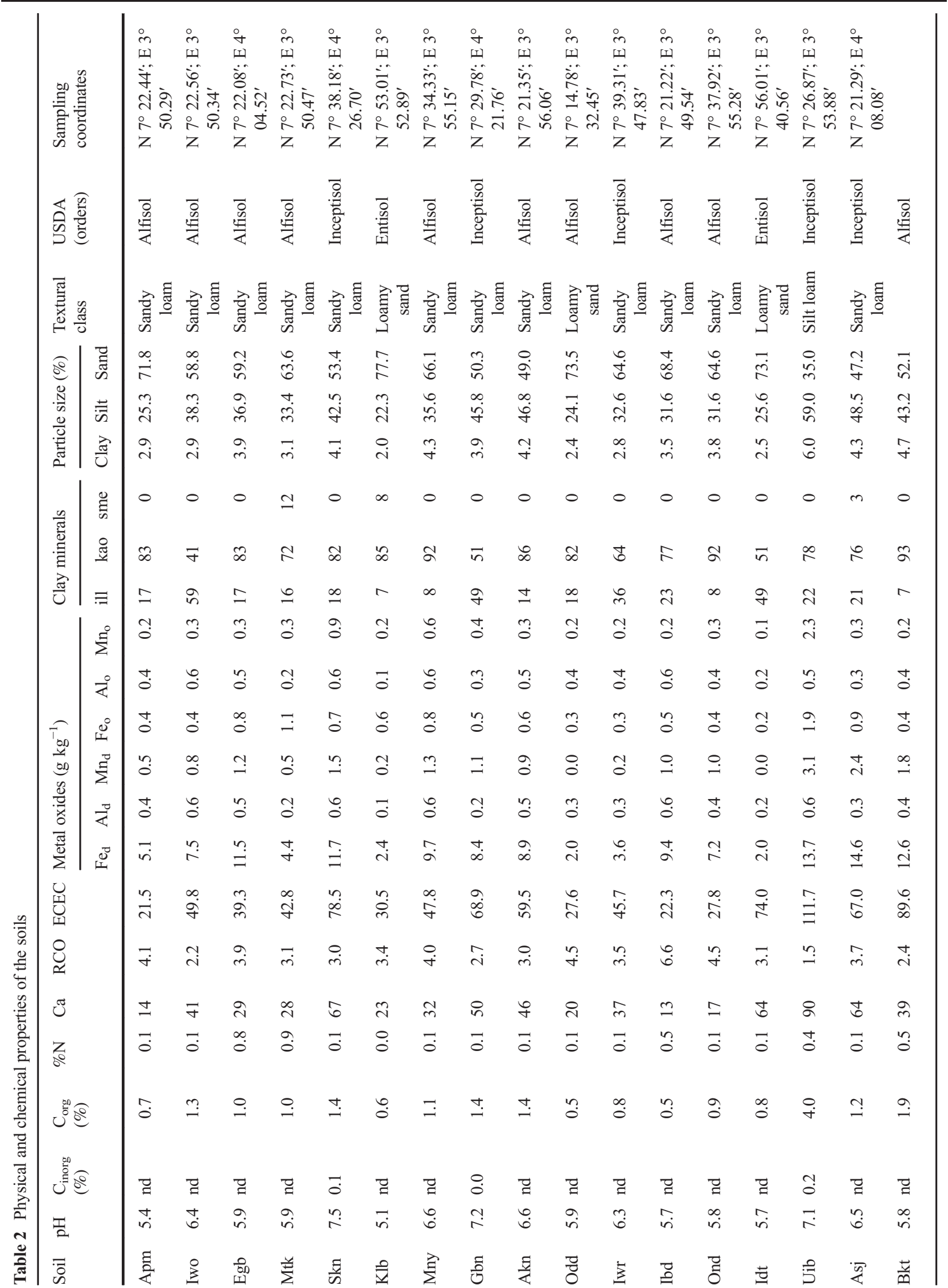


(5-cycle) oxidation with hot $3 \mathrm{M} \mathrm{NaOCl}$ (14\% active $\mathrm{Cl}$ ). After the complete treatment, the $\mathrm{pH}$ of the samples was controlled and readjusted repeatedly until the final $\mathrm{pH}$ of the residues was the same as those of the original soils. Finally, the residues were washed several times with deionised water and air-dried. The samples were subsequently labelled as omf (organic matter free). This method was used particularly as it favours significantly minimal modifications of the soil mineral constituents (Lavkulich and Wiens 1970; Mikutta et al. 2005).

\section{Sorption experiments}

All sorption experiments were carried out using the batch equilibrium method, according to the OECD 106 guideline (OECD 2000). For the sorption isotherm experiments, soil ( $2 \mathrm{~g}$ dry weight (dw) per sample) was weighed into $50-\mathrm{mL}$ polypropylene tubes, to equilibrate with $20 \mathrm{~mL}$ of $0.01 \mathrm{M} \mathrm{CaCl}_{2} /$ Milli-Q water solutions of each pesticide, at concentrations ranging from 0.25 to $25 \mathrm{mg} \mathrm{L}^{-1}$. The suspensions were continuously shaken (with an end-over-end shaker, at $8 \mathrm{rpm}$ ) at $20^{\circ} \mathrm{C} \pm 1{ }^{\circ} \mathrm{C}$ for $24 \mathrm{~h}$ in the dark and then centrifuged at $4000 \mathrm{rpm}$ for $15 \mathrm{~min}$. For sorption kinetic experiments, soil (1 g dw per sample) was weighed into $50-\mathrm{mL}$ polypropylene tubes, to equilibrate with $10 \mathrm{~mL}$ of $20 \mathrm{mg} \mathrm{L}^{-1}$ (for linuron and diuron) and $10 \mathrm{mg} \mathrm{L}^{-1}$ (for monuron), in $0.01 \mathrm{M} \mathrm{CaCl}_{2} / \mathrm{Milli}^{-Q}$ water solutions. The suspensions were continuously shaken and subsequently treated as described above, with a set of tubes withdrawn at time intervals $(20 \mathrm{~min}, 40 \mathrm{~min}, 90 \mathrm{~min}, 180 \mathrm{~min}$ and $360 \mathrm{~min}$ ) to obtain sorption data at different periods of time. In both experiments, the supernatants were filtered with $0.2-\mu \mathrm{m}$ Phenex RC membrane filters (Phenomenex, Torrance, USA), and the filtrate was collected into $2-\mathrm{mL}$ amber $\mathrm{LC}$ vials and measured immediately with HPLC or kept in refrigerator at $4{ }^{\circ} \mathrm{C}$ (for a maximum of 2 days) prior to analysis. All experiments were conducted in duplicates and at soil natural $\mathrm{pH}$. Since the results of several pre-studies showed very low data variability, this number of parallels is justified. Blank samples and control tests (in the same tubes and conditions as the sorption tests) were also run in parallel as quality control measures. From preliminary investigations, no significant adsorption of the test compounds occurred on the experimental tubes, neither were residues of the test compounds found in the experimental soils. Apart from their reported half-lives (in soils) extending far beyond the test period, compounds were also 
established to be relatively stable during the sorption experiment from repeated preliminary tests.

Pesticide analysis

Analyses were carried out with a Shimadzu 10ADvp HPLC system (Shimadzu, Duisburg, Germany), equipped with a photodiode array detector (SPDM20A, Prominence). The column was a $\mathrm{C}_{18}$ reversedphase Hypersil (length, $250 \mathrm{~mm}$; inner diameter, $4 \mathrm{~mm}$; particle size, $5 \mu \mathrm{m}$; Thermo Fisher Scientific, Dreieich, Germany), and the sample injection volume was $20 \mu \mathrm{L}$. An isocratic eluent, composed of methanol $/ 2.5 \%$ acetic acid Milli-Q water solution (60/40 v/v), was applied at a flow rate of $0.5 \mathrm{~mL} \mathrm{~min}{ }^{-1}$. Other parameters are presented in Table 1. Data were collected and processed with LabSolutions software (Shimadzu, Duisburg, Germany). Quantification was based on seven-point calibration functions covering a concentration range of 0.1$25 \mathrm{mg} \mathrm{L}^{-1}$ for each analyte. The achieved coefficients of determination $\left(r^{2}\right)$ were greater than 0.99. All samples were analysed in triplicate, and the within-runs $\mathrm{CVs}$ were below $5 \%$.

\section{Evaluation of sorption data}

It was assumed that the differences between the added concentrations $\left(C_{0}, \mathrm{mg} \mathrm{L}^{-1}\right)$ and the equilibrium concentrations in the aqueous phase $\left(C_{\mathrm{e}}, \mathrm{mg} \mathrm{L}^{-1}\right)$ (directly determined from the HPLC measurements) were solely due to sorption. Therefore, the amount adsorbed by the solid phase $\left(Q_{\mathrm{e}}, \mathrm{mg} \mathrm{kg}^{-1}\right)$ was calculated based on mass balance as follows:

$$
Q_{\mathrm{e}}=\left(\frac{C_{0}-C_{\mathrm{e}}}{m_{\mathrm{s}}}\right) \times V
$$

where $V(\mathrm{~L})$ is the volume of the solution, and $m_{\mathrm{s}}$ is the mass of the soil $(\mathrm{kg})$.

The percentage sorbed of PUH $(S(\%))$ was calculated as

$S(\%)=\left(\frac{C_{0}-C_{\mathrm{e}}}{C_{0}}\right) \times 100$

The linear distribution coefficient of the sorption $\left(K_{\mathrm{d}}\right.$, $\mathrm{L} \mathrm{kg}^{-1}$ ) was calculated as

$K_{\mathrm{d}}=Q_{\mathrm{e}} / C_{\mathrm{e}}$
This was normalised on the basis of SOC to obtain $K_{\mathrm{oc}}$ (i.e. $K_{\mathrm{oc}}=K_{\mathrm{d}} / f_{\mathrm{oc}}$ ), where $f_{\mathrm{oc}}$ (soil organic carbon fraction) is given as $\mathrm{SOC} / 100$.

Further, the $K_{\mathrm{d}}$ of organic compounds in soils was expressed as the sum of two contributions: $K_{\text {d.mineral }}$ that accounts for sorption by soil minerals (i.e. all soil constituents other than SOM), which could be significant in soils with low SOM, and $K_{\text {d.organic }}$ that corresponds to (ad)sorption by the SOM (Millinovic et al. 2015; Delle Site 2001). The relationship is presented in Eq. (5).

$$
\begin{aligned}
K_{\text {d.soil }} & =K_{\text {d.organic }}+K_{\text {d.mineral }} \\
& =K_{\mathrm{oc}} \times f_{\mathrm{oc}}+K_{\text {d.mineral }}
\end{aligned}
$$

Arising from this expression, the average value of $K_{\mathrm{oc}}$ for a given PUH was derived from the slope of $K_{\text {d.soil }}$ vs $f_{\text {oc }}$, while the intercept on the $y$-axis gave an estimate of the average $K_{\text {d.mineral }}$.

Sorption isotherms were constructed by plotting $Q_{\mathrm{e}}$ vs $C_{\mathrm{e}}$ for each PUH-soil combination. Also, isotherm data were fitted to the Freundlich model which is the most frequently used model for hydrophobic compounds (Hinz 2001). The Freundlich model is quantitatively described by Eqs. (6) and (7).

$Q_{\mathrm{e}}=K_{\mathrm{f}} \cdot\left(C_{\mathrm{e}}\right)^{n}$

which transforms to the logarithmic form

$\log Q_{\mathrm{e}}=n \log C_{e}+\log K_{\mathrm{f}}$

where $n$ is a dimensionless empirical parameter that provides an indication of the isotherm linearity (i.e. $n=$ 1 for a linear isotherm), and $K_{\mathrm{f}}$ is the specific Freundlich sorption coefficient expressed as $\left(\mathrm{mg} \mathrm{kg}^{-1}\right)\left(\mathrm{mg} \mathrm{L}^{-1}\right)^{-n}$. $K_{\mathrm{f}}$ and $n$ were calculated by linear least squares fitting of the sorption isotherms. $K_{\mathrm{f}}$ was also normalised on the basis of the SOC to obtain $K_{\text {foc }}$ (i.e. $K_{\text {foc }}=K_{\mathrm{f}} / f_{\text {oc }}$ ).

To mathematically describe the intrinsic kinetic adsorption mechanisms, the kinetic data were fitted to two widely applied models, i.e. pseudo-first-order (PFO) and pseudo-second-order (PSO) (Eqs. (8) and (9), respectively).

$\log \left(Q_{\mathrm{e}}-Q_{t}\right)=-\frac{k_{1}}{2.303} t+\log Q_{\mathrm{e}}$ 
$\frac{t}{Q_{t}}=\left(\frac{1}{Q_{\mathrm{e}}}\right) t+\frac{1}{k_{2} Q_{e}{ }^{2}}$

where $Q_{t}$ is the amount of pesticide adsorbed $\left(\mathrm{mg} \mathrm{kg}^{-1}\right)$ at any time $(t, \min ) ; k_{1}\left(\mathrm{~min}^{-1}\right)$ and $k_{2}$ $\left(\mathrm{kg} \mathrm{mg}^{-1} \mathrm{~min}^{-1}\right.$ ) are the rate constants of PFO and PSO, respectively; and $Q_{\mathrm{e}}$ is as previously described. The initial adsorption rate $\left(h, \mathrm{mg} \mathrm{kg}^{-1} \mathrm{~min}^{-1}\right)$ is given by $k_{2} Q_{\mathrm{e}}{ }^{2}$.

All calculations, plots and development of regression equations were done with Microsoft Excel ${ }^{\circledR}$ (2013), while correlation analysis and test of significance were done with R-project open source software. Specifically, linear and multiple correlations were performed between the selected pesticide properties and the sorption coefficients $\left(K_{\mathrm{f}}\right.$ and $\left.K_{\mathrm{d}}\right)$, between the sorption coefficients and the soil properties and among soil properties themselves, using the Pearson product moment correlation (PPMC). The Pearson correlation coefficient $(r)$ was calculated as Eq. (10). Also, the goodness of fit of the regression equations was determined with the coefficient of determination $\left(R^{2}\right)$, given as Eq. (11).

$r=\frac{n\left(\sum x y\right)-\left(\sum x\right)\left(\sum y\right)}{\sqrt{\left[n \sum x^{2}-\left(\sum x\right)^{2}\right]}\left[n \sum y^{2}-\left(\sum y\right)^{2}\right]}$

$R^{2}=1-\frac{\sum_{i}\left(x_{i}-y_{i}\right)^{2}}{\sum_{i}\left(x_{i}-\frac{1}{n} \sum_{i=0}^{n} x\right)^{2}}$

\section{Results and discussion}

\section{Soil characteristics}

Since one of the main goals of this study was to determine the most important soil-specific properties that influence sorption, we selected soils that represented a wide range of geochemical properties. The main physicochemical characteristics of the soils as well as their descriptive statistics are presented in Table 2. With the exception of Skn, Gbn, Uib, Iwo, Mny, Akn, Iwr and Asj which were slightly neutral (6.3-7.5), all other soils were acidicwith a $\mathrm{pH}$ range of 5.4 to 5.9. Organic carbon ranged from $0.5 \%$ (Ibd and Odd) to $4 \%$ (Uib). The ECEC ranged from $21.5 \mathrm{mmol}_{\mathrm{c}} \mathrm{kg}^{-1}$ (Apm) to $111.7 \mathrm{mmol}_{\mathrm{c}} \mathrm{kg}^{-1}$ (Uib).
Uib also had the highest cumulative amount of pedogenic and free metal oxides $\left(22.10 \mathrm{~g} \mathrm{~kg}^{-1}\right)$, while Odd has the least amount $\left(2.72 \mathrm{~g} \mathrm{~kg}^{-1}\right)$. Particle size analysis showed that all the soils had low clay contents in the range 2.4$6.0 \%$, while silt proportion ranged from 24.1 to $59 \%$. Uib had the highest percentage of both clay and silt (6\% and $59 \%$, respectively), while Odd had the least of both ( $2.4 \%$ and $24 \%$, respectively). XRD analysis revealed the presence of quartz, microcline and albite in all samples, while few samples contain sodalite, calcite and dolomite in addition (figures not shown). Semiquantitative analysis of the clay indicated the presence of 2:1 expansive clay smectite (a compound name for montmorillonite, beidellite, nontronite and saponite) in only Mtk, Klb and Asj (at 12.3\%, 7.9\% and 2.6\%, respectively), in addition to illite (a 2:1 non-expansive clay mica) and kaolinites (a 1:1 non-expansive clay) which were present in all soils. Generally, kaolinite and illite ranged from 7.4 to $59.4 \%$ and from 40.7 to $92.6 \%$, respectively, in all soils. Using the United States Department of Agriculture (USDA) soil texture classification, thirteen (13) of the soils were sandy loam, four (Odd, Idt, Asj and Fas) were loamy sand, while only Uib was silty loam.

\section{Sorption kinetics}

Figure $2 \mathrm{a}, \mathrm{b}$ and c respectively displays linuron (LIN), diuron (DIU) and monuron (MON) sorption profiles with time, for twelve selected soils. Generally from the decline curves, a three-step kinetic process was observed: a rapid adsorption at the initial stage from $t=0$ to $t=30 \mathrm{~min}$, followed by a slow rate-limiting second stage and then the final long constant stage (reaching an apparent equilibrium between 120 and $180 \mathrm{~min}$ for the three compounds, in most of the soils). This observation is attributed to the heterogenous nature of soil (Morrica et al. 2000; Morrilo et al. 2000). Multi-stage sorption process of organic contaminants in soils/sediments has been reported (Pan et al. 2012). This initial fast adsorption suggests that PUHs may not undergo rapid seepage into the ground water upon discharge on the soil. The later slow adsorption would constitute the ratedetermining step for the other (bio)geochemical interactions of the compounds with soils. Figure 2 further depicts that the adsorption rates decreased with time until equilibrium was attained at $180 \mathrm{~min}$. However, we observed slight reversibility of LIN in few of 
a)
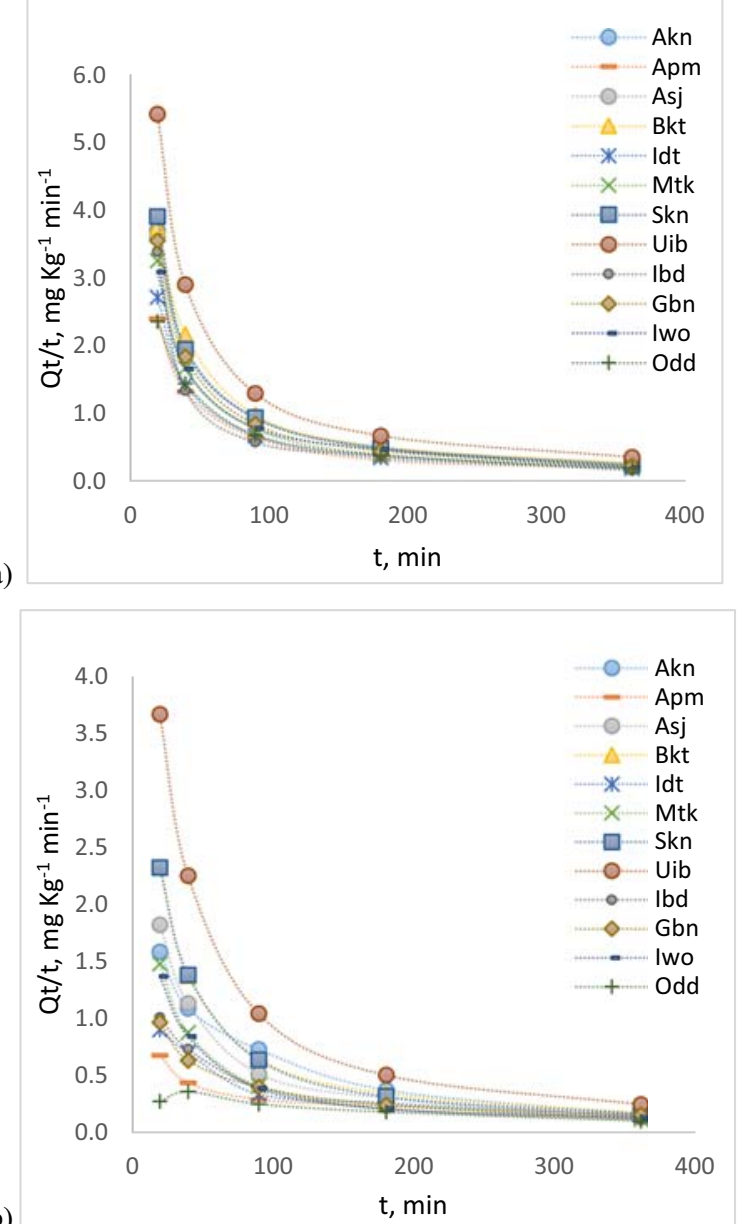

b)

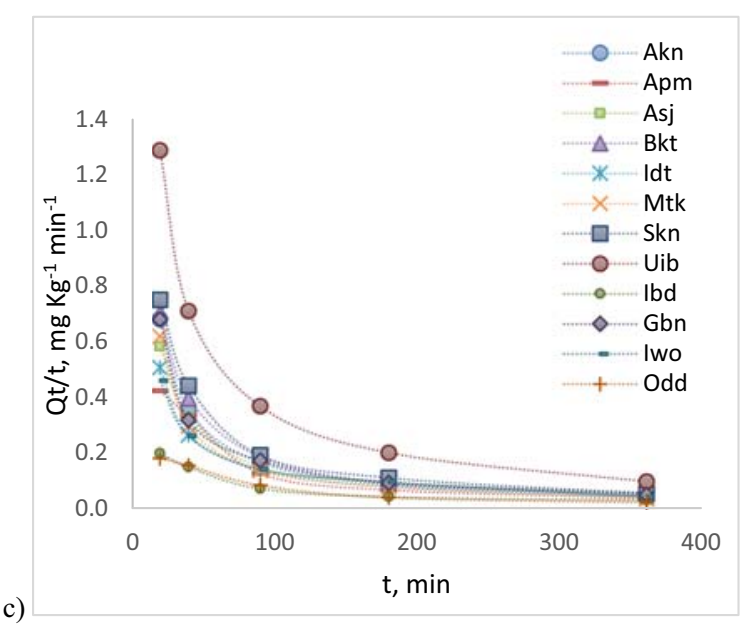

Fig. 2 Sorption kinetic profiles of a linuron, $\mathbf{b}$ diuron and $\mathbf{c}$ monuron

the soils (especially Ibd) after $180 \mathrm{~min}$. This observation may be connected to their SOM content. Ibd, for instance, has the least SOM. Thus, most of the sorption occurred on the soil minerals which are easier to desorb. The weak adsorption of non-ionic solutes on soil minerals may be attributed to the stronger competitive adsorption of water for the polar mineral surfaces (Chiou 2002). This often leads to the formation of outer-sphere surface complexes with generally less stable bonds (Sposito 2008).

$\mathrm{PFO}$ and PSO equations were used to fit the kinetic data in order to derive the kinetic parameters and to identify the kinetic mechanism(s) involved. However, only PSO showed very good fits, with $R^{2}$ ranging from 0.96 to 1.0 . Thus, only PSO parameters are selectively presented (supplementary material, SM1). It is thus observed that the theoretical $Q_{\mathrm{e}}\left(Q_{\mathrm{e} \text { model }}\right)$ fairly agreed with the experimental $Q_{\mathrm{e}}$, and both followed the trend of SOC, and $\log K_{\text {ow }}$ and Mw (of the compounds). The initial adsorption rate $(h)$ also fairly correlated with $\log$ $K_{\text {ow }}$ and the Mw of the compounds, but its trend with soil properties, most importantly SOC, was not readily discernible. No relationship was found between $k_{2}$ and either the soil properties or the molecular descriptors $\left(\log K_{\text {ow }}\right.$ and $\left.\mathrm{Mw}\right)$.

\section{Sorption isotherms}

The shapes of isotherm curves provide an overview of the relationship between sorbate and adsorbent at equilibrium (Giles et al. 1960). The isotherm plots of the five PUHs in all the soils are shown in SM2. Further, to confirm the linearity or otherwise of $Q_{\mathrm{e}}$ vs $C_{\mathrm{e}}$ and to deduce the sorption coefficients of each PUH-soil system, the isotherm data were fitted to the Freundlich equation. Table 3 shows the values of the sorption parameters ( $n$ and $K_{\mathrm{f}}$ ) obtained from the Freundlich fittings, as well as the $K_{\mathrm{d}}$ average (which is the mean of the $K_{\mathrm{d}}$ values for the six concentration levels). For all cases, satisfactory fittings were obtained with coefficient of determination $\left(R^{2}\right)$ ranging from 0.94 to 1.00 (figures not shown). The value of $n$ represents a joint measure of both the relative magnitude and diversity of energies associated with a particular sorption process (Delle Site 2001). In this study, we observed $n<1$ in all cases (Table 3 ). While it ranged from 0.3 to 0.4 for chlorotoluron (CLT), it was close to unity for the remaining four compounds. Isoproturon (IPU), in particular, had a very high $n$ value $(0.9)$ in Ond. Generally, $n<1$ represents a convex, downward-curved, Langmuir-type (L-type) 


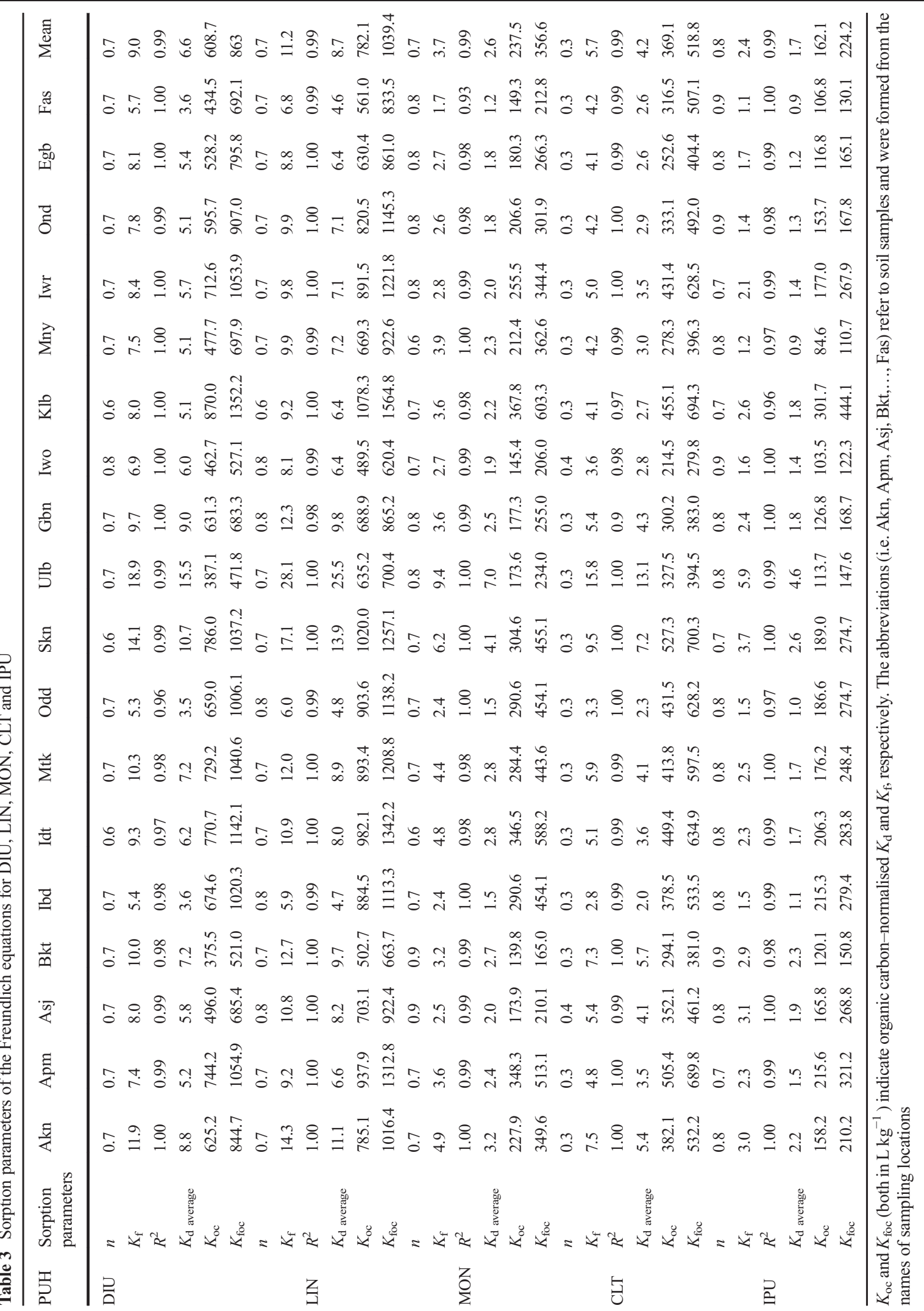

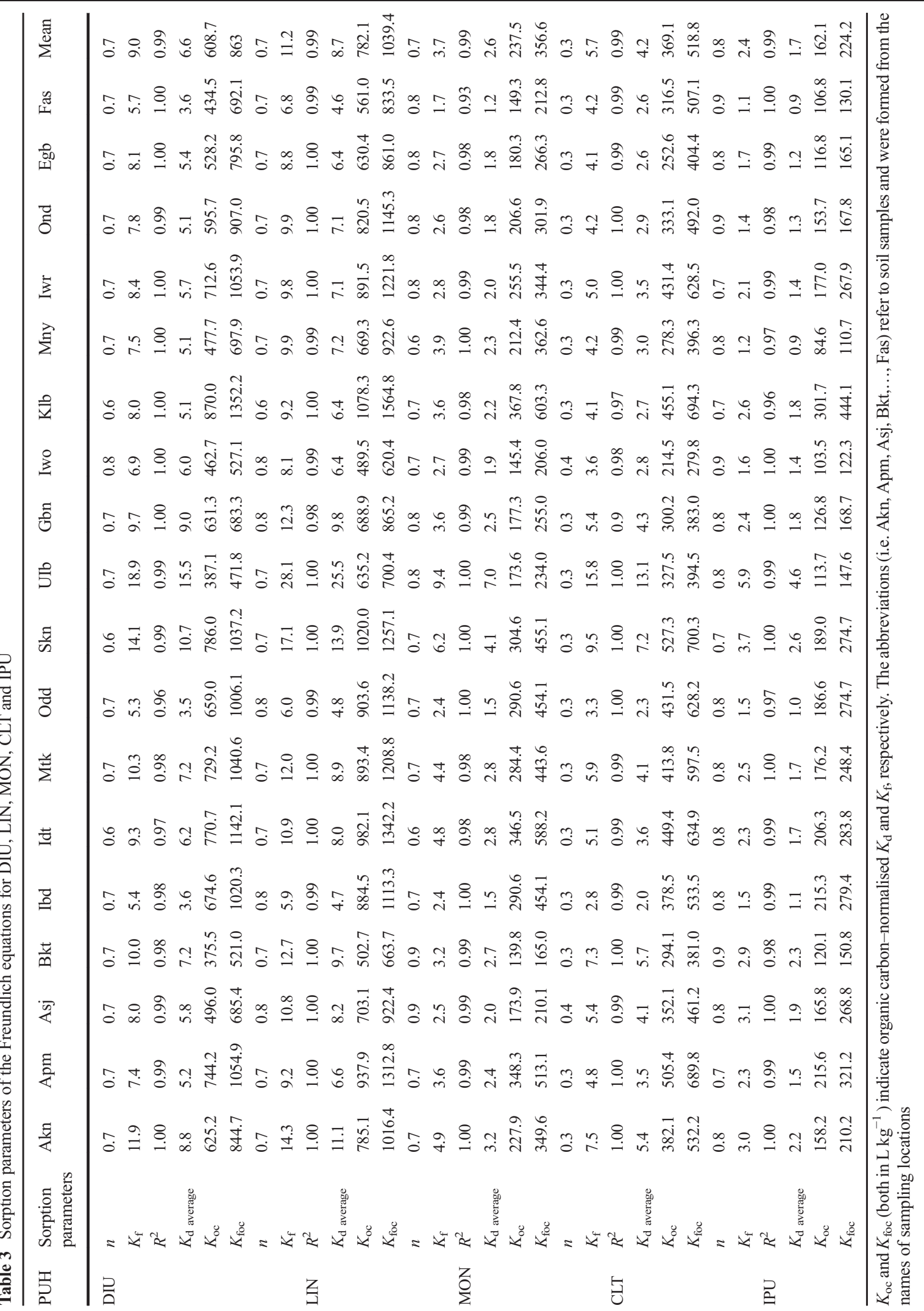

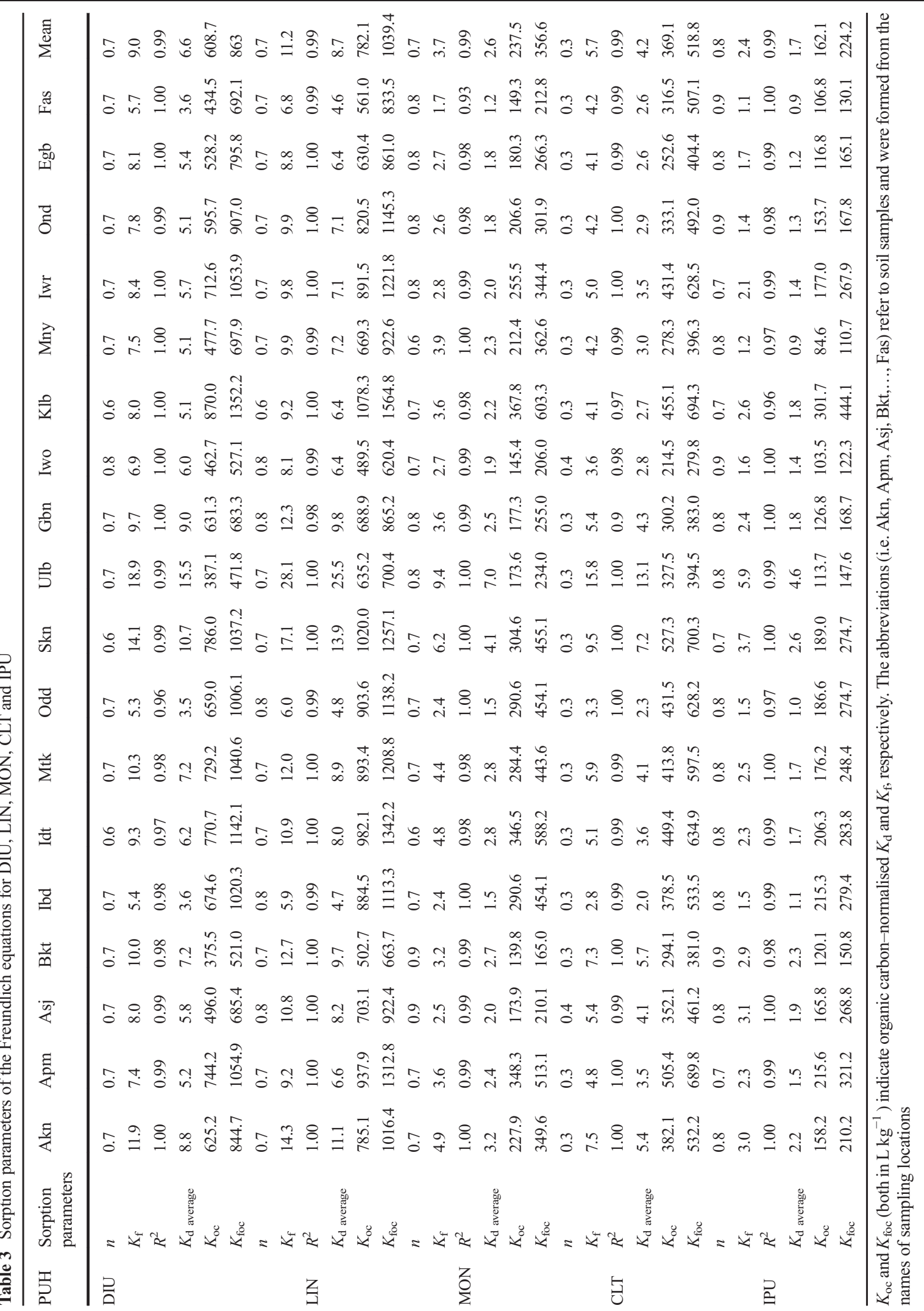


isotherm (Giles et al. 1960), and it is the most common type of sorption interactions between herbicides and soils (Petter et al. 2017). It indicates that the marginal sorption energy decreases with increasing surface concentration and often arises where the competition of solvent for sites is minimal or the adsorbate is a planar molecule (Delle Site 2001). $n$ values close to 1 indicate a seemingly constant partitioning of the compounds in SOM. On the other hand, $n$ values close to 0 indicate a predominance of adsorption onto soil minerals.

Based on the molecular structure (substituted aromatic ring), sorption of PUHs may result basically from hydrophobic interactions in solutions and from van der Waals/specific interactions in the sorbed phase (Spurlock and Biggar 1994). While hydrophobic interaction accounts for the adsorption by SOM which could be by $\pi$-stacking between the phenyl moiety and the soil surface, the following specific interactions with soil minerals and/or hydrophilic moieties are possible: (1) interaction between the double-bonded oxygen of the carbonyl and a hydrogen atom of the clay lattice, (2) hydrogen bonding between the $\mathrm{NH}$ group of the aryl ammonium ions and the silicate layer and (3) hydrogen bonding through the water bridge formed by the primary hydration shell of clay cation (i.e. between the organic compound and the clay complex). These specific interactions are directional in nature (i.e. site directed). Therefore, the value of the Freundlich number (n) also reflects the complex interplay between sorbate properties (polarity, size, shape) and sorbent properties (physical [e.g. steric] or chemical [e.g. electronic]). The further $n$ deviates from unity-as it was found in CLT, the greater the degree of sitespecific interaction (Rae et al. 1998).

The sorption coefficients $\left(K_{\mathrm{d} \text { average, }} K_{\mathrm{oc}}\right.$ and $\left.K_{\mathrm{foc}}\right)$ are also presented in Table 3 . The $K_{\mathrm{d}}$ average values reported here are the means of six concentration levels. In all soils, LIN recorded the highest values for all the coefficients, followed by DIU, CLT, MON and IPU, in that order. The highest values of these parameters are associated with Uib which has the highest values of virtually all the soil parameters, while the least values alternate between Odd, Ibd and Fas (which are soils that have the lowest values of most of the parameters). The mean $K_{\mathrm{f}}$ of the five compounds and their trend with SOC are presented in Fig. 3 ( $a$ and b, respectively).
Basically, it could be observed that LIN has the highest $K_{\mathrm{f}}$ in all the soils, followed by DIU, CLT, $\mathrm{MON}$ and IPU, in that order. Also, it was observed that the highest $K_{\mathrm{f}}$ values correspond to soil (Uib) with the highest SOC, while the least values correspond to the soils (Odd and Ibd) with the lowest SOC (Fig. 3b).

Arising from the plots of $K_{\mathrm{d}} \mathrm{vs} f_{\mathrm{oc}}$ (SM3), we obtained the following regression equations: $564.74 x+1.98$ for LIN, $328.68 x+2.71$ for DIU, $305.81 x+0.56$ for IPU, $144.01 x+0.85$ for MON and $96.64 x+0.59$ for CLT. Although the regression coefficients $\left(R^{2}\right)$ were not so close to unity $(0.78-0.87)$, we could still fairly deduce $K_{\mathrm{oc}}$ values from the plots (Eq. (5)). Consequently, we found that LIN has the highest $K_{\mathrm{oc}}(565)$, followed by DIU (329), IPU (306), MON (144) and CLT (97). Expectedly, these values are respectively lower than our reported averages for these compounds (Table 3). However, except for CLT, the values gave fair estimates of the adjusted $K_{\mathrm{oc}}$; one may obtain after subtracting the $K_{\text {d.mineral }}$ from the $K_{\text {d.soil }}$. From the plots also, the order of the sorption to soil mineral was DIU $>$ LIN $>$ MON $>$ CLT $>$ IPU, with estimated $K_{\text {d.mineral }}$ values of 2.71 (DIU), $1.98(\mathrm{LIN}), 0.85(\mathrm{MON}), 0.59$ (CLT) and 0.56 (IPU). These values indicated that $K_{\text {dmineral }}$ contributed between 15 and $40 \%$ to the $K_{\mathrm{d} \text { average reported }}$ for these compounds (Table 3 ). In other words, it indicates that soil mineral fractions, vis-à-vis clay minerals and the amorphous metal oxides, also contributed fairly significantly (about 15-40\%) to the sorption of the five test compounds in the soils. Sanchez-Camazano et al. (2000) have also reported significant adsorption of urea herbicides by clays. Nevertheless, Morrill et al. (1982) have reported that humic substances occur in intimate contact with other soil constituents, and that mineral-SOM interactions determine the adsorptive capacity of each soil. In fact, soil organic matters are said to exist as coatings on clay minerals, forming soil organo-clay complexes. The relationships between sorption coefficients, SOC and other soil physical and chemical properties were further explored in a later section.

Sorption on organic matter-free soils

The positive relationship between pesticide sorption and SOM has been widely reported. Thus, SOM has been assumed to be the primary constituent responsible for inactivating pesticides (Weber et al. 2004). We also investigated the contribution of SOM to the sorption coefficients reported in our study. Table 4 shows the SOC of the selected 4 samples before and after organic 
a)

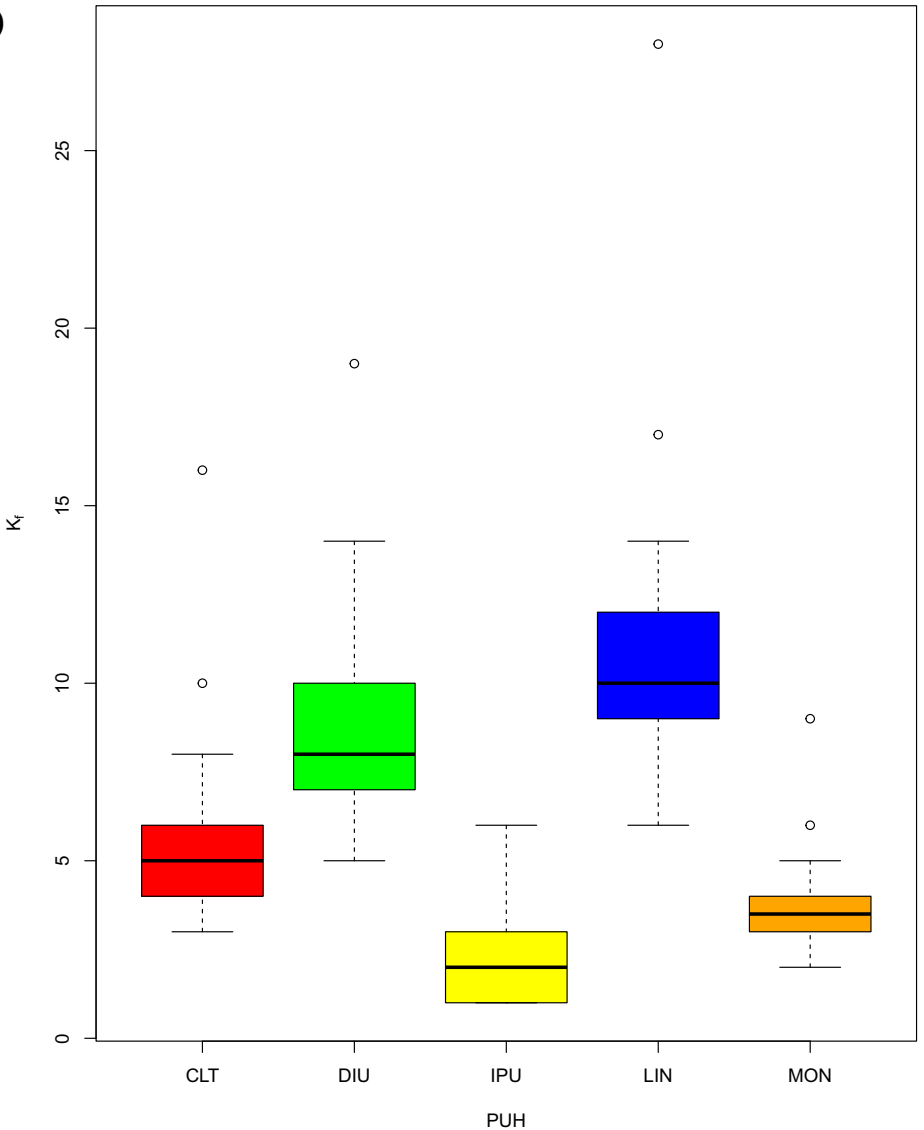

b)

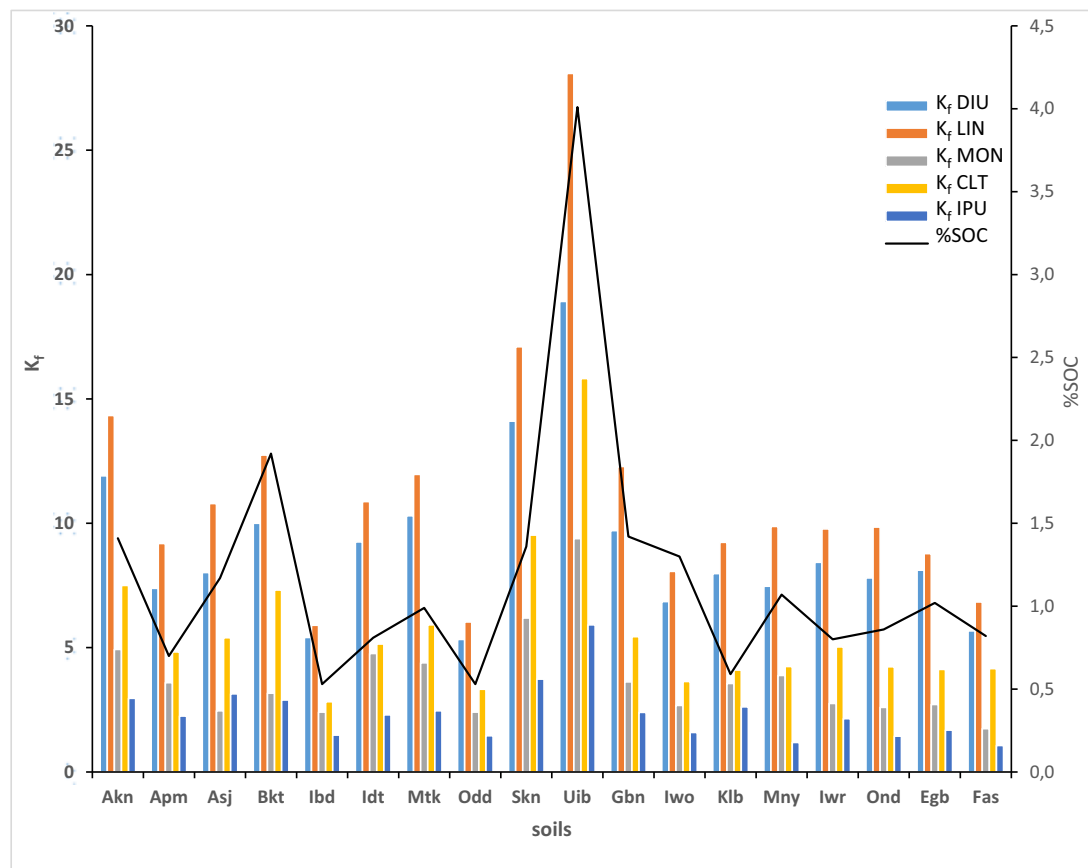

Fig. 3 a Boxplots showing the mean $K_{\mathrm{f}}$ of the five compounds (the median is marked by the horizontal line inside the inner rectangle; the whiskers above and below the inner rectangle respectively represent the locations of the maximum and minimum, while the circles represent suspected outliers. b Charts of $K_{\mathrm{f}}$ and its trend with SOC 
Table 4 SOC, $K_{\mathrm{f}}$ and $K_{\mathrm{d}}$ for whole soils and omf

\begin{tabular}{llllllllll}
\hline Samples & SOC ws & SOC omf & $\%$ SOC removed & $K_{\mathrm{f}}$ ws & $K_{\mathrm{f}}$ omf & $\% K_{\mathrm{f}}$ reduction & $K_{\mathrm{d}}$ ws & $K_{\mathrm{d}}$ omf & $\% K_{\mathrm{d}}$ reduction \\
\hline Apm. DIU & 0.7 & 0.05 & 93 & 7.4 & 0.7 & 91 & 5.2 & 0.6 & 89 \\
Gbn. DIU & 1.4 & 0.09 & 93 & 9.7 & 0.8 & 92 & 9.0 & 0.6 & 93 \\
Ibd. DIU & 0.6 & 0.03 & 94 & 5.4 & 0.5 & 90 & 3.6 & 0.5 & 86 \\
Uib. LIN & 4.3 & 1.06 & 75 & 29.2 & 6.7 & 77 & 28.4 & 5.4 & 81 \\
\hline
\end{tabular}

ws whole soil, omf organic matter-free soil

matter removal treatment. It was observed that except in Uib where the SOC was reduced by only $75 \%$, the treatment achieved between 93 and $96 \%$ reductions in the SOC of the other three soils.

It was also observed that the sorption coefficients for the treated soils were lowered by the corresponding percentage of the reduction in their SOC. This confirmed the dominating effect of SOM in the sorption of PUHs.

\section{Correlations between variables}

\section{Intercorrelations between soil basic parameters}

The intercorrelations between the basic properties of the soils used in this study were described with Pearson correlation coefficients, and the results are presented in Table 5. In summary, $\mathrm{pH}$ was found to have positive and significant correlations with SOC, exchangeable $\mathrm{Ca}$, ECEC, $\mathrm{Al}_{\mathrm{d}}, \mathrm{Mn}_{\mathrm{o}}$, \%clay and \%silt and a very significant negative correlation with \%sand. SOC showed highly significant and strong positive correlations with exchangeable $\mathrm{Ca}, \mathrm{ECEC}, \mathrm{Fe}_{\mathrm{d}}, \mathrm{Fe}_{\mathrm{o}}, \mathrm{Mn}_{\mathrm{d}}, \mathrm{Mn}_{\mathrm{o}}$, \%clay and $\%$ silt. Generally, soil cation exchange capacity (CEC) is largely determined by the charge of the soil particles and SOM (Morrill et al. 1982). Especially in the highly weathered tropical soils, where clay fraction is predominantly composed of oxides and hydroxides of $\mathrm{Fe}, \mathrm{Al}$ and $\mathrm{Mn}$ (as in the present study) and kaolinite (1:1 silicate clays of low reactivity), the CEC is due largely to SOM (Mendes et al. 2014). It is therefore not surprising that samples with high amounts of clay and/or organic matter typically have higher CEC than sandy soils. ECEC showed significant correlations with $\mathrm{Mn}_{\mathrm{d}}$, $\mathrm{Mn}_{\mathrm{o}}$, \%clay, \%silt and \%sand. Extractable Fe and $\mathrm{Mn}$ oxides also showed significantly high and positive correlations with \%clay and \%silt and negative correlations with \%sand. Some of these observations have been made by Agboola and Corey (1973), by Inoue et al.
(2006) for tropical soils and by Weber et al. (2004) for temperate soils.

\section{Correlations between sorption coefficients and basic soil parameters}

Table 5 also presents the correlations between soil basic properties and sorption equilibria $\left(K_{\mathrm{f}}\right.$ and $\left.K_{\mathrm{d}}\right)$ for the five test compounds. The results showed $K_{\mathrm{f}}$ and $K_{\mathrm{d}}$ of the five PUHs having positive significant correlations with $\mathrm{pH}(r=0.51-70, p \leq 0.034)$ and $\mathrm{Fe}_{\mathrm{o}}(r=0.60-0.68$, $p<0.01)$ and very strong and highly significant correlations with $\% \mathrm{C}_{\mathrm{org}}(r=0.83-0.94, p=0.0000)$, ECEC $(r=0.74-0.84, p=0.0000)$, exchangeable $\mathrm{Ca}(r=0.74$ $0.82, p<0.001), \mathrm{Mn}_{\mathrm{o}}(r=0.76-0.88, p=0.0000)$, $\%$ clay $(r=0.69-0.74, p<0.001)$ and \%silt $(r=0.71-$ $0.79, p=0.0000)$. Various studies have underscored the dominance of SOC in the sorption of various organic compounds, especially the non-ionisable ones like PUHs (Coquet and Barriuso 2002; Cooke et al. 2004; Ertli et al. 2004; Inoue et al. 2006; El-Khattabi et al. 2007; Fernandez-Bayo et al. 2008; Tian et al. 2010; ElNahhal et al. 2013). By the same token, very strong relationships have also been reported between sorption coefficients of PUHs and some other soil parameters such as clay content and $\mathrm{pH}$, in addition to SOC (ElNahhal et al. 2013). For instance, $\mathrm{pH}$ was reported as the second most important factor after SOM, for influencing the adsorption of phenylureas by temperate soils (Coquet and Barriuso 2002). But contrary to this finding, our study has shown that ECEC and amorphous Fe and $\mathrm{Mn}$ oxides (i.e. $\mathrm{Fe}_{\mathrm{o}}$ and $\mathrm{Mn}_{\mathrm{o}}$ ) exert higher influence than $\mathrm{pH}$ on PUH adsorption by tropical soils. Coquet (2003) and Weber et al. (2004) also reported that sorption of PUHs was correlated with the clay content and the composition of the clay particle for temperate soils. Our study has also confirmed this and has generally underscored the importance of soil minerals in sorption 


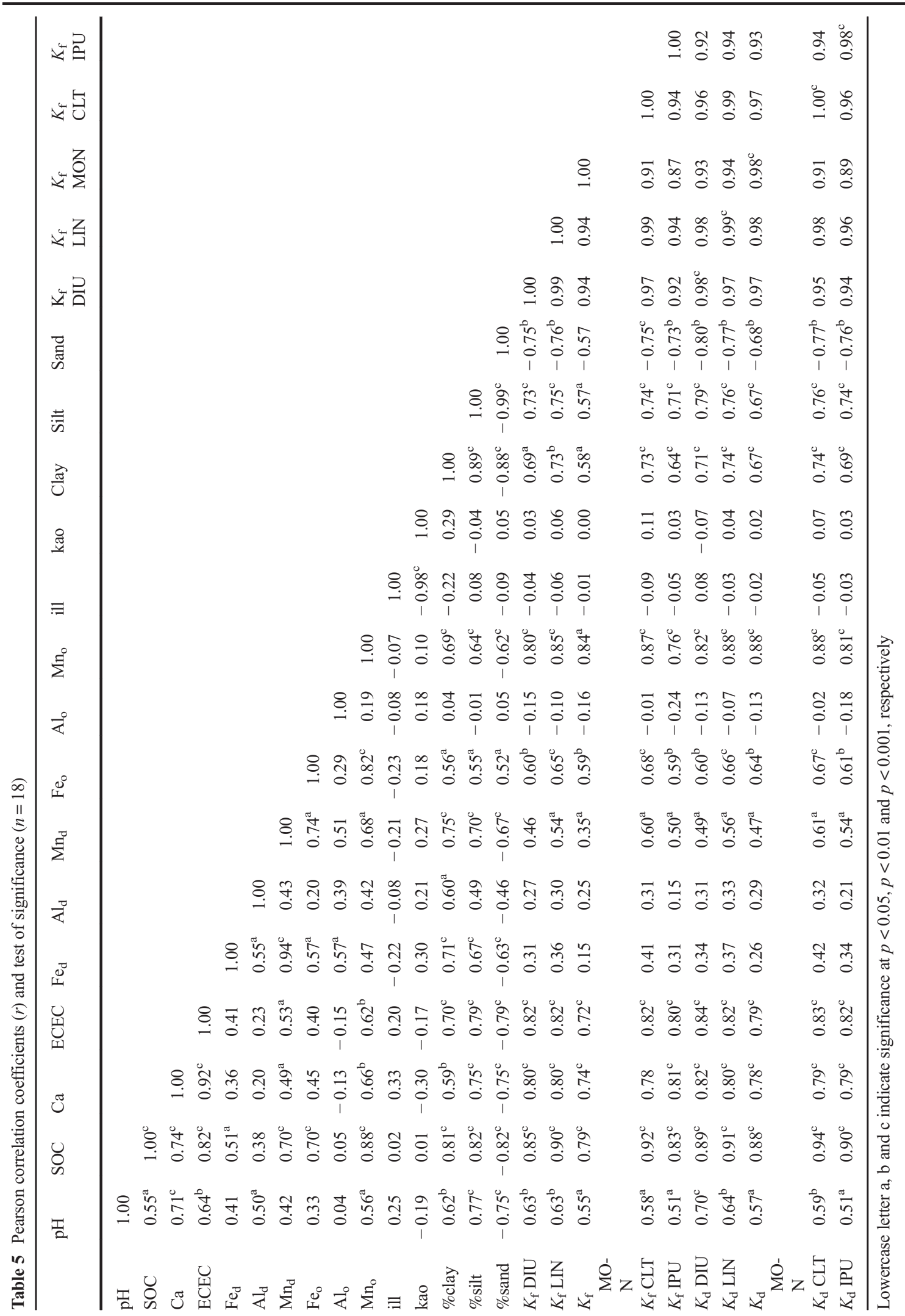


Table 6 Pearson correlation coefficients $(r)$ of $K_{\mathrm{f}}$ and $K_{\mathrm{d}}$ with PUH molecular descriptors

\begin{tabular}{lcrrrrr}
\hline & $\log K_{\text {ow }}$ & \multicolumn{1}{l}{ Mw } & $\alpha$ & \multicolumn{1}{l}{$S$} & $\log S$ & $\log \alpha$ \\
\hline $\log K_{\text {ow }}$ & 1.0 & & & & & \\
$\mathrm{Mw}$ & $0.9^{\mathrm{a}}$ & 1.0 & & & & \\
$\alpha$ & 0.8 & 0.5 & 1.0 & & & \\
$\mathrm{~S}$ & $-0.9^{\mathrm{a}}$ & -0.6 & -0.9 & 1.0 & & \\
$\log S$ & $-0.9^{\mathrm{a}}$ & -0.6 & -0.9 & 1.0 & 1.0 & \\
$\log \alpha$ & 0.8 & 0.5 & 1.0 & -0.9 & -0.9 & 1.0 \\
$K_{\mathrm{f} \text { mean }}$ & 0.8 & $1.0^{\mathrm{a}}$ & 0.2 & -0.4 & -0.4 & 0.2 \\
$K_{\mathrm{d} \text { mean }}$ & 0.8 & $1.0^{\mathrm{b}}$ & 0.2 & -0.4 & -0.4 & 0.2 \\
$K_{\mathrm{f} \text { min }}$ & 0.7 & $0.9^{\mathrm{a}}$ & 0.2 & -0.4 & -0.4 & 0.2 \\
$K_{\mathrm{f} \text { max }}$ & 0.8 & $0.9^{\mathrm{a}}$ & 0.2 & -0.4 & -0.4 & 0.2 \\
$K_{\mathrm{d} \text { min }}$ & 0.8 & $1.0^{\mathrm{b}}$ & 0.2 & -0.4 & -0.5 & 0.3 \\
$K_{\mathrm{d} \text { max }}$ & 0.7 & $0.9^{\mathrm{a}}$ & 0.2 & -0.4 & -0.5 & 0.2 \\
\hline
\end{tabular}

Lowercase letters $\mathrm{a}, \mathrm{b}$ and $\mathrm{c}$ indicate significance at $p<0.05, p<$ 0.01 and $p<0.001$, respectively

min minimum, max maximum

of non-ionisable herbicides by low organic matter soils such as the ones used in this study.

\section{Correlation with PUH properties}

Out of the four PUH molecular properties checked for correlation, only $\log K_{\mathrm{ow}}$ and $\mathrm{Mw}$ showed very strong correlations with all the variants of $K_{\mathrm{f}}$ and $K_{\mathrm{d}}$ of the compounds studied (Table 6). Mw, in particular, showed a significant correlation $(p \leq 0.01)$. Normally with the trends of both $\log K_{\mathrm{ow}}$ and molecular mass (Mw), the order of the sorption coefficients expected was LIN > DIU $>$ CLT $>$ IPU $>$ MON. Surprisingly however, results in this study showed a slight deviation, with MON which has the least $\log K_{\text {ow }}$ and Mw having higher $K_{\mathrm{f}}$ and $K_{\mathrm{d}}$ values than IPU. Therefore, the order of the sorption coefficients $\left(K_{\mathrm{f}}\right.$ and $\left.K_{\mathrm{d}}\right)$ followed the sequence LIN $>$ DIU $>$ CLT $>$ MON $>$ IPU. Except for this inversion between MON and IPU, our results could have followed strictly the trend observed by FouqueBrouard and Fournier (1996), Weber et al. (2004) and Blondel et al. (2013) for temperate soils. Other PUH molecular descriptors considered (i.e. polarisability index and solubility, and their log transformed values) did not show any strong relationships with the sorption equilibria. This is in agreement with the findings of Theng (1974) for solubility and Hance (1965) for polarisability.
Generally, the increase in adsorption with an increase in the molecular weight has been explained by Traube (Kipling 1965). According to him, as the molecular weight of the adsorbate increases, the surface activity also increases, leading to displacement of more water molecules, with the larger molecules having more points of contact with the adsorbent. The overall effect of this is net entropy and net enthalpy gains. Exception to this rule is found in the case of high molecular weight compounds such as polymers. In the same vein, the increase in adsorption with an increase in $\log K_{\text {ow }}$ is adduced to hydrophobic interactions between the PUH and the organic moiety of the soil. Even though much of the soil organic moiety (in soil humus) is not electrically charged, nevertheless, the PUHs which are themselves uncharged (non-ionic) can react strongly with the uncharged moiety through van der Waals interactions. Although the van der Waals interaction between two molecules is always very weak, when many molecules in a polymeric structure like humus interact simultaneously, the van der Waals interaction creates a synergy and therefore becomes strong, often much stronger than the interaction between PUHs and soil water. This results in their adsorption from the soil solution by humus. According to Sposito (2008), this occurs for two distinct reasons: hydrophobic effect and the presence of nonpolar moieties in SOM. However, hydrophobic effect can be exacerbated by the presence of electron withdrawing substituents, especially chlorine. Chlorine is a highly electronegative atom that, upon replacing $\mathrm{H}$ atom on a carbon atom, withdraws significant electron charge density carbon-carbon bonds in chain or ring structures, thus rending them less polar and more hydrophobic.

Consequently, LIN and DIU which have two chlorine atoms each (Table 1) recorded higher $K_{\mathrm{f}}$ and $K_{\mathrm{d}}$ values than MON and CLT which have one, while MON and CLT recorded higher sorption than IPU that has none. These observations have also been made by Blondel et al. (2013). On the other hand, the difference in the adsorption coefficients of LIN and DIU seems to be caused by the substituents in R1 (Table 1). The presence of a methoxy group in LIN as against a methyl group in DIU confers higher adsorption on LIN. The same observation was made by Blondel et al. (2013), FouqueBrouard and Fournier (1996) and Grover (1975). CLT has higher $K_{\mathrm{f}}$ and $K_{\mathrm{d}}$ values than MON, despite both having one chlorine each on the phenyl ring. This is a result of (i) the difference in the position of the chlorine atom (i.e. meta in MON and para in CLT). A substituent 


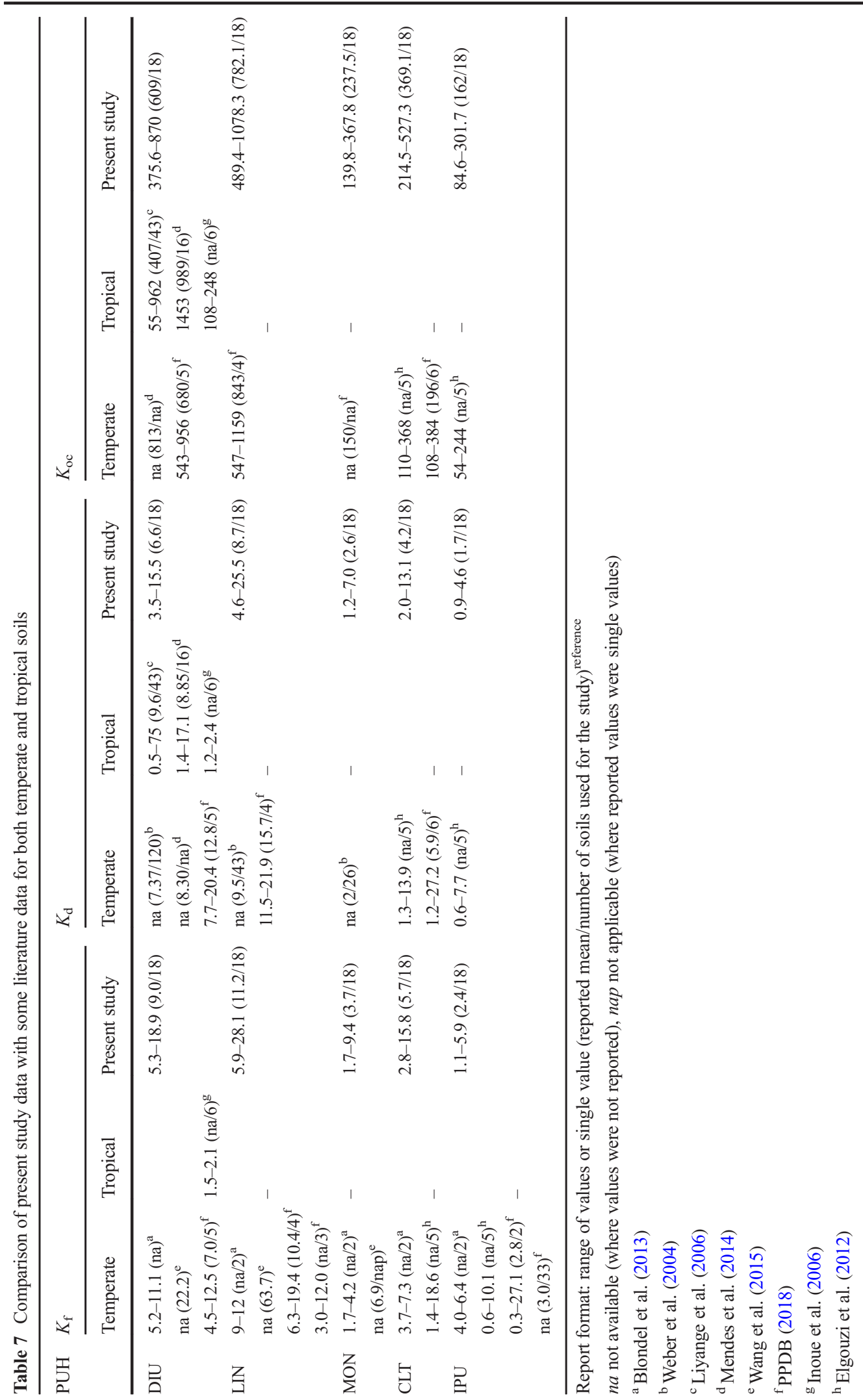


in para position confers higher hydrophobicity (and hence higher adsorption) on a compound than a similar substituent in meta position, and (ii) the presence of methyl group in CLT. According to Hance (1965), an increase in $n$-aliphatic chain length or additional aryl substitutions in urea herbicides leads to greater adsorption by soil. In the same token, CLT has higher $K_{\mathrm{f}}$ value than IPU despite both having the same $K_{\mathrm{ow}}$. This observation can be attributed to the presence of chlorine atom in the former and the absence of it in the latter, as earlier explained. The observation of Hance (1965) earlier stated is subservient here.

Comparison of the sorption coefficients in Nigerian soils with published data

To see if our data differ remarkably from those published in the literature (on both tropical and temperate soils), we presented (where available) the reported ranges and means of $K_{\mathrm{f}}, K_{\mathrm{d}}$ and $K_{\mathrm{oc}}$ for the five compounds in comparison with the results of this study (Table 7). This discussion will however be limited to comparison of the SOC normalised sorption coefficient $\left(K_{\mathrm{oc}}\right)$ values since they are even derived from $K_{\mathrm{d}}$ (most often) or $K_{\mathrm{f}}$. For DIU, our values (376-870) fall outside the range 543-956 reported by PPDB (2018) for European soils and the range 107.6-247.5 reported for Brazilian soils by Inoue et al. (2006). They however fall within the ranges 55.3-962 and 145-2.631 reported for tropical soils of Sri Lanka and Brazil, respectively, by Liyange et al. (2006) and Mendes et al. (2014). Our mean $K_{\mathrm{oc}}$ value of 609 is strikingly different from all reported means, for either temperate or tropical soils, but falls within the range of the reported means (i.e. 480813 for temperate soils and 407-989 for tropical soils). For LIN, our values (489-1078) fall within the range 547-1159 reported by PPDB (2018). However, the reported means are also different, i.e. 782 (this study) against 843 (PPDB 2018). PPDB (2018) reported a mean $K_{\mathrm{oc}}$ value of 150 for MON which is considerably lower than our value (237). Our values (215-527; mean, 369) for CLT are quite higher compared to 110-368 and 108-384 (mean, 196) reported by both Elgouzi et al. (2012) and PPDB (2018), respectively, for temperate soils. The same observation could be made about IPU: we reported the value 85-302 (mean, 162), while Elgouzi et al. (2012) reported 54-244. This comparison is however not comprehensive.

\section{Conclusion}

It is indisputable that an understanding of the sorption mechanism is fundamental for predicting the fate of organic contaminants in the environment. With respect to pesticide-soil interactions, the environmentally essential distribution of phenylurea herbicides between soil and soil water has always been estimated by measuring $K_{\mathrm{f}}$ or $K_{\mathrm{d}}$ values. While there exists relatively large data of sorption coefficients of some of the PUHs in temperate soils, there are just very few data on sorption equilibria of these compounds in tropical soils. More so, those few by Liyange et al. (2006), Inoue et al. (2006) and Mendes et al. (2014) were only on diuron. It is therefore very difficult to make valid comparison with other data from tropical soils. Nevertheless, the attained ranges of sorption data for DIU and LIN in this study were within the ranges reported for temperate soils, while those of MON, CLT and IPU were outside the ranges obtained from temperate soils. Thus, our hypothesis that PUHs sorbed differently to tropical and temperate soils can only be said to be partly confirmed. Oliver et al. (2005) which compared sorption of diuron in Australian (temperate) soils and Filipino (tropical) soils also concluded that they were the same. Therefore, to answer the question whether the existing data on sorption coefficients of this group of herbicides from temperate soils can be extrapolated for tropical soils, more studies and/or a larger database on their sorption coefficients in tropical soils may be needed. This was also the conclusion of Liyange et al. (2006). From correlation analysis, this study has shown that not only SOM but also CEC and soil mineral fractions (i.e. clay/silt and amorphous $\mathrm{Fe}$ and $\mathrm{Mn}$ oxides) are important soil parameters that largely explain the variations in PUH sorption by tropical soils, with SOM being the most prominent. Particularly, our study has shown hitherto unrevealed correlation (in either temperate or tropical soils) between PUH adsorption and amorphous Mn oxides. Lastly, as expected, the sorption coefficients showed high correlations $(0.8)$ with $\log K_{\mathrm{ow}}$, but much higher and significant correlations (1.0) with Mw. Thus, the molecular mass of these compounds would be a better predictor for their sorption behaviour than $\log K_{\text {ow }}$.

Acknowledgements The authors like to thank the Soil Science, Geology, and Hydrology Departments of University of Trier, Germany, for their technical assistance in the characterisation of the soil samples. 
Funding Information Open Access funding provided by Projekt DEAL.

Open Access This article is licensed under a Creative Commons Attribution 4.0 International License, which permits use, sharing, adaptation, distribution and reproduction in any medium or format, as long as you give appropriate credit to the original author(s) and the source, provide a link to the Creative Commons licence, and indicate if changes were made. The images or other third party material in this article are included in the article's Creative Commons licence, unless indicated otherwise in a credit line to the material. If material is not included in the article's Creative Commons licence and your intended use is not permitted by statutory regulation or exceeds the permitted use, you will need to obtain permission directly from the copyright holder. To view a copy of this licence, visit http://creativecommons.org/licenses/by/4.0/.

\section{References}

Agboola, A. A., \& Corey, R. B. (1973). The relationship between soil $\mathrm{pH}$, organic matter, available phosphorus, exchangeable potassium, calcium, magnesium and nine elements in the maize. Journal of Soil Science, 115, 367-375.

Baskeyfield, D. E. H., Davis, F., Magan, N., \& Tothill, I. E. (2011). A membrane-based immunosensor for the analysis of the herbicide isoproturon. Analytica Chimica Acta, 699(2), 223-231.

Biscaye, P. E. (1965). Mineralogy and sedimentation of recent deep-sea clay in the Atlantic Ocean and adjacent seas and oceans. Geological Society of America Bulletin, 76, 803-832.

Blondel, A., Langeron, J., Sayen, S., Henon, E., Couderchet, M., \& Guillon, E. (2013). Molecular properties affecting the adsorption coefficients of phenylurea herbicides. Environmental Science and Pollution Research, 20, 62666281.

Chhokar, R. S., Singh, S., \& Sharma, R. K. (2008). Herbicides for control of isoproturon resistant littleseed canarygrass (Phalaris minor) in wheat. Crop Protection, 27, 719-726.

Chiou, C. T. (2002). Partition and adsorption of organic contaminants in environmental systems. Hoboken: Wiley Interscience. John Willy and Sons Inc.

Cooke, C. M., Shaw, G., \& Collins, C. D. (2004). Determination of solid-liquid partition coefficients $\left(\mathrm{K}_{\mathrm{d}}\right)$ for the herbi cides isoproturon and trifluralin in five UK agricultural soils. Environmental Pollution, 132, 541-552.

Coquet, Y. (2003). Variation of pesticide sorption isotherm in soil at the catchment scale. Pest Management Science, 58, 69-78.

Coquet, Y., \& Barriuso, E. (2002). Spatial variability of pesticide adsorption within the topsoil of a small agricultural catchment. Agronomie, 22(4), 389-398.

Delle Site, A. (2001). Factors affecting sorption of organic compounds in natural sorbent/water systems and sorption coefficients for selected pollutants. A review. Journal of Physical and Chemical Reference Data, 30(1), 187-439.

Elgouzi, S., Mingorance, M. D., Draoui, K., Chtoun, E. H., \& Peña, A. (2012). Assessment of phenylurea herbicides sorption on various Mediterranean soils affected by irrigation with wastewater. Chemosphere, 89, 334-339.

El-Khattabi, K., Bouhaouss, A., Scrano, L., Lelario, F., \& Bufo, S. A. (2007). Influence of humic fractions on retention of isoproturon residues in two Moroccan soils. Journal of Environmental Science and Health, Part B: Pesticides, Food Contaminants, and Agricultural Wastes, 42, 851-856.

El-Nahhal, Y., Abadsa, M., \& Affifi, S. (2013). Adsorption of diuron and linuron in Gaza soils. Journal of Analytical Chemistry, 4, 94-99.

Eriksson, E., Baun, A., Mikkelsen, P. S., Ledin, A. (2007). Risk assessment of xenobiotics in stormwater discharged to Harrestrup Å, Denmark. Desalination, 215(1-3), 187-197.

Ertli, T., Marton, A., \& Foldenyi, R. (2004). Effect of $\mathrm{pH}$ and the role of organic matter in the adsorption of isoproturon on soils. Chemosphere, 57, 771-779.

Fagbemi, A. A., \& Shogunle, E. A. A. (1995). Nigeria: reference soils of the coastal swamps near Ikorodu Lagos state. Soil brief 2 (p. 17). Wageningen: University of Ibadan, Ibadan, and International Soil Reference and Information Centre.

Federico, C., Pappalardo, M., Leotta, C. G., Minniti, Z., Librando, V., \& Saccone, S. (2014). Phenylurea herbicides: chemical properties and genotoxic effects. In D. Kobayashi \& E. Watanabe (Eds.), Handbook on herbicides. New York: Nova Science Publishers, Inc.

Fernandez-Bayo, J. D., Nogales, R., \& Romero, E. (2008). Evaluation of the sorption process for imidacloprid and diuron in eight agricultural soils from Southern Europe using various kinetic models. Journal of Agricultural and Food Chemistry, 56, 5266-5278.

Fouque-Brouard, C. M., \& Fournier, J. M. (1996). Adsorptiondesorption and leaching of phenyurea herbicides on soils. Talanta, 43, 1973-1802.

Ghafoor, A., Jarvis, N. J., Thierfelder, T., \& Stenstrom, J. (2011). Measurements and modelling of pesticide persistence in soil at the catchment scale. Science of the Total Environment, 409, 1900-1908.

Giacomazzi, S., \& Cochet, N. (2004). Environmental impact of diuron transformation: a review. Chemosphere, 56, 10211032.

Giles, C. H., MacEwan, T. H., Nakhwa, S. N., \& Smith, D. (1960). Studies in adsorption. Part XI. A system of classifica tion of solution adsorption isotherms, and its use in diagnosis of adsorption mechanisms and in measurement of specific surface areas of solids. Journal of the Chemical Society, 39733993.

Giresse, P. (2008). Characteristics of the soils and present day vegetation of tropical West Africa. In Developments in quaternary science (Vol. 10, pp. 15-18).

Green, P. G., \& Young, T. M. (2006). Loading of the herbicide diuron into the California water system. Environmental Engineering Science, 23, 545-551.

Grover, R. (1975). Adsorption and desorption of urea herbicides on soils. Canadian Journal of Soil Science, 55, 127-133.

Hall, K. E., Ray, C., Ki, S. J., Spokas, K. A., \& Koskinen, W. C. (2015). Pesticide sorption and leaching potential on three Hawaiian soils. Journal of Environmental Management, 159, 227-234.

Hance, R. J. (1965). The adsorption of urea and some of its derivatives by a variety of soils. Weed Research, 5, 98-107. 
Hinz, C. (2001). Description of sorption data with isotherm equations. Geoderma, 99, 225-243.

Inoue, M. H., Oliveira Jr., R. S., Regitano, J. B., Tormena, C. A., Constantin, J., \& Tornisielo, V. L. (2006). Sorptiondesorption of atrazine and diuron in soils from southern Brazil. Journal of Environmental Science and Health, Part B: Pesticides, Food Contaminants, and Agricultural Wastes, 41, 605-621.

IUSS Working Group WRB. (2014). World reference base for soil resources 2014. In P. Schad, C. van Huyssteen, \& E. Micheli (Eds.), World soil resources reports no. 106. Rome: FAO 189 p. ISBN 978-92-5-108369-7.

Karickhoff, S. W. (1984). Semi empirical estimation of sorption of hydrophobic pollutants on natural sediments and soils. Chemosphere, 10, 833.

Kipling, J. J. (1965). Adsorption from solutions of non-electrolytes, Ch. 3. London: Academic.

Langeron, J., Blondel, A., Sayen, S., Henon, E., Couderchet, M., \& Guillon, E. (2014). Molecular properties affecting the adsorption of pesticides from various chemical families. Environmental Science and Pollution Research. https://doi. org/10.1007/s11356-014-2916-6.

Lavkulich, L. M., \& Wiens, J. H. (1970). Comparison of organic matter destruction by hydrogen peroxide and sodium hypochlorite and its effects on selected mineral constituents. Soil Science Society of America Journal, 64, 1608-1615.

Liyange, J. A., Watawala, R. C., Aravina, G. P., Smith, L., \& Kookana, R. S. (2006). Sorption of carbofuran and diuron pesticides in 43 soils of Sri Lanka. Journal of Agricultural and Food Chemistry, 54(5), 1784-1791.

Lu, G. H., Hou, K. K., \& Liu, J. C. (2018). Sorption and desorption of selected phenylurea herbicides in laboratory watersediment systems. IOP Conference Series: Earth and Environmental Science, 191, 012021.

Mehra, O. P., \& Jackson, M. L. (1960). Iron oxides removal from soils and clays by dithionate citrate system buffered with Nabicarbonate. Clays and Clay Minerals, 5, 317-327.

Mendes, K. F., Reis, M., Reis, D., Carolina, A., Dias, R., Formiga, J. A., Christoffoleti, P., \& Tornisielo, V. L. (2014). A proposal to standardize herbicide sorption coefficients in Brazilian tropical soils compared to temperate soils. Journal of Food, Agriculture and Environment, 12(3\&4), 424-433.

Mikutta, R., Kleber, M., Kaiser, K., \& Jahn, R. (2005). Organic matter removal from soils using hydrogen peroxide, sodium hypochlorite, and disodium peroxodisulfate. A review. Soil Science Society of America Journal, 69, 120-135.

Millinovic, J., Lacorte, S., Vidal, M., \& Rigol, A. (2015). Sorption behavior of perflouroalkyl substances in soils. Sci. Total Environ., 511, 63-71.

Morrica, P., Barbato, F., Giordano, A., Seccia, S., \& Ungaro, F. (2000). Adsorption and desorption of imazosulfuron by soil. Journal of Agricultural and Food Chemistry, 48(12), 61326137.

Morrill, L. G., Mahilum, B. C., \& Mohiuddin, S. H. (1982). Organic compounds in soils: sorption, degradation and persis tence. Ann Arbor: Ann Arbor Science Publishers, Inc..

Morrilo, E., Undabeytia, T. A., \& Ramos, C. M. (2000). Glyphosate adsorption on soils of different characteristics. Influence of copper addition. Chemosphere, 40(1), 103-107.
Murphy, E. M., \& Zachara, J. M. (1995). The role of sorbed humic substances on the distribution of organic and inorganic contaminants in groundwater. Geoderma, 67, 103-124.

OECD. (2000). Guidelines for testing of chemicals: adsorptiondesorption using a batch equilibrium method. Paris: Organisation for Economic Cooperation and Development, OECD 106.

Oliver, D. P., Kookana, R. S., \& Quintana, B. (2005). Sorption of pesticides in tropical and temperate soils from Australia and the Philippines. Journal of Agricultural and Food Chemistry, $53,6420-6425$.

Olvera-Velona, A., Benott, P., Barriuso, E., \& Ortiz-Hernandez, L. (2008). Sorption and desorption of organophosphate pesticides, parathion and cadusafos, on tropical agricultural soils. Agronomy for Sustainable Development, 28, 231-238.

Orton, F., Lutz, I., Kloas, W., \& Routledge, E. J. (2009). Endocrine disrupting effects of herbicides and pentachlorophenol: in vitro and in vivo evidence. Environmental Science \& Technology, 43(6), 2144-2150.

Pan, B., Wang, P., Wu, M., Li, J., Zhang, D., Xiao, D. (2012). Sorption kinetics of ofloxacin in soils and mineral particles. Environmental Pollution, 171, 185-190.

Petter, F. A., Ferreira, T. S., Sinhorin, A. P., Lima, L. B., Almeida, F. A., Pacheco, L. P., \& Silva, A. F. (2017). Biochar increases diuron sorption and reduces the potential contamination of subsurface water with diuron in a sandy soil. Pedosphere, 29(6), 801-809.

PPDB. (2018). The Pesticide Properties Database (PPDB) developed by the Agriculture and Environment Research Unit $(A E R U)$. Hatfield: University of Hertfordshire.

Rae, J. E., Cooper, C. S., Parker, A., \& Peters, A. (1998). Pesticide sorption onto aquifer sediments. Journal of Geochemical Exploration, 64, 263-276.

Rao, P. S. C., Hornsby, A. G., \& Jessup, R. E. (1985). Indices for ranking the potential for pesticide contamination of groundwater. Soil and Crop Science Society of Florida Proceedings, 44(1), 1-8.

Sanchez-Bayo, F., \& Hyne, R. V. (2011). Comparison of environmental risks of pesticides between tropical and non tropical regions. International Environmental Assessment and Management, 7(4), 577-586.

Sanchez-Camazano, M., Sanchez-Martin, M. J., \& DelgadoPascual, R. (2000). Adsorption and mobility of linuron in soils as influenced by soil properties, organic amendments, and surfactants. Journal of Agricultural and Food Chemistry, $48,3018-3026$.

Schwertmann, U. (1964). Differenzierung der Eisenoxide des Bodens durch Extraktion mit Ammoniumoxalat-Lösung. Journal of Plant Nutrition and Soil Science, 105(3), 194 202.

Shuman, L. M., \& Duncan, R. R. (1990). Soil exchangeable cations and aluminum measured by ammonium chloride, potassium chloride, and ammonium acetate. Communications in Soil Science and Plant Analysis, 21(13), 1217-1228.

Silkina, A., Brazes, A., Vouve, F., Le Tilly, V., Douzenel, P., Mouget, J. L., \& Bourgougnon, N. (2009). Antifouling activity of macroalgal extracts on Fragilaria pinnata (Bacillariphyceae): a comparison with diuron. Aquatic Toxicology, 94, 245-254.

Sørensen, S. R., Bending, G. D., Jacobsen, C. S., Walker, A., \& Anmand, J. (2003). Microbial degradation of isoproturon and 
related phenylurea herbicides in and below agricultural fields. FEMS Microbiology Ecology, 45, 1-11.

Sposito, G. (2008). The chemistry of soils. Oxford: Oxford University Press, Inc.

Spurlock, C. F., \& Biggar, J. W. (1994). Thermodynamics of organic chemical partition in soils. 2. 58. Nonlinear partition of substituted phenylureas from aqueous solution. Environmental Science \& Technology, 28, 996-1002.

Tamm, O. (1922). Medd. Skogsforsoeksues, 19, 387.

Theng, B. K. G. (1974). The chemistry of clay-organic reactions. New York: Wiley.

Tian, C., Wang, M. D., \& Si, Y. B. (2010). Influences of charcoal amendment on adsorption-desorption of isoproturon in soils. Agricultural Sciences in China, 9, 257-265.
Wang, D., Mukome, F. N. D., Yan, D., Wang, H., Scow, K. M., \& Parikh, S. J. (2015). Phenylurea herbicides sorption to biochars and agricultural soil. Journal of Environmental Science and Health, Part B, 50, 544-551.

Weber, J. B., Wilkerson, G. G., \& Reinhardt, C. F. (2004). Calculating pesticide sorption coefficients $\left(\mathrm{K}_{\mathrm{d}}\right)$ using selected soil properties. Chemosphere, 55, 157-166.

Publisher's note Springer Nature remains neutral with regard to jurisdictional claims in published maps and institutional affiliations. 